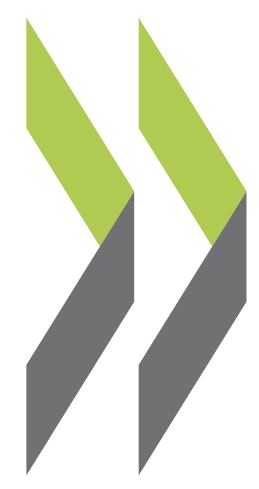

OECD Regional Development Working Papers 2017/05

Subnational Infrastructure Investment in OECD

Countries: Trends and Key Governance Levers
Dorothée Allain-Dupré,

Claudia Hulbert,

Margaux Vincent 


\section{OECD REGIONAL DEVELOPMENT WORKING PAPERS}

This series is designed to make available to a wider readership selected studies on regional development issues prepared for use within the OECD. Authorship is usually collective, but principal authors are named. The papers are generally available only in their original language English or French with a summary in the other if available.

OECD Working Papers should not be reported as representing the official views of the OECD or of its member countries. The opinions expressed and arguments employed are those of the author(s).

This document, as well as any [statistical] data and map included herein, are without prejudice to the status of or sovereignty over any territory, to the delimitation of international frontiers and boundaries and to the name of any territory, city or area.

Working Papers describe preliminary results or research in progress by the author(s) and are published to stimulate discussion on a broad range of issues on which the OECD works. Comments on Working Papers are welcomed, and may be sent to the Centre for Entrepreneurship, SMEs, Local Development and Tourism, OECD, 2 rue André-Pascal, 75775 Paris Cedex 16, France.

Authorised for publication by Lamia Kamal-Chaoui, Director, Centre for Entrepreneurship, SMEs, Local Development and Tourism, OECD.

OECD Regional Development Working Papers are published on http://www.oecd.org/cfe/regional-policy/

(C) OECD 2017

You can copy, download or print OECD content for your own use, and you can include excerpts from OECD publications, databases and multimedia products in your own documents, presentations, blogs, websites and teaching materials, provided that suitable acknowledgement of OECD as source and copyright owner is given. All requests for public or commercial use and translation rights should be submitted to rights@oecd.org. 


\title{
SUBNATIONAL INFRASTRUCTURE INVESTMENT IN OECD COUNTRIES: TRENDS AND KEY GOVERNANCE LEVERS
}

\author{
By \\ Dorothée Allain-Dupré, Claudia Hulbert and Margaux Vincent ${ }^{1}$
}

\begin{abstract}
:
Public investment is one of the fiscal tools with the strongest impacts on growth over the long term. However, public investment is in decline compared to the period prior to the 2008 global financial crisis in many OECD countries, and particularly in the EU. The main explanation for the decreased resources available for investment comes from the expenditure side. Subnational governments (SNGs) - defined as all levels of government (regional and local) below the national level, are responsible for a large share of public investment: on average, around 60 per cent in the OECD. Most of this public investment goes to infrastructure. This particular role of SNGs poses specific challenges for both the financing and governance of infrastructure investment. This paper focuses on subnational public investment in OECD countries and the EU, and shows that subnational governments have decreased their capital expenditures after 2010. This adjustment has been larger than at the central government level. The paper argues that only a limited diversification of public investment financing has occurred since 2010. The paper also argues that, beyond the sheer volume of investment spending, the governance of subnational investment is essential to efficient public investment. Based on a 2015 survey of 255 subnational governments in the EU, this paper explores specific challenges that subnational governments encounter in managing capital expenditures, and possible ways to improve the quality of governance of subnational investments.
\end{abstract}

\section{JEL classification: JEL $-\mathrm{H} 7$}

Keywords: Infrastructure, Investment, Governance, Regional, Cities, Territorial, Regional Economics.

\footnotetext{
${ }^{1}$ The authors would like to thank Isabelle Chatry, Antoine Comps, Varinia Michalun and Isidora Zapata who provided inputs in the paper. They are also grateful for comments received on initial versions of this paper in 2016 from Luiz de Mello, Jean-Marc Fournier, Joaquim Oliveira Martins, Karen Maguire, Monica Brezzi, and Ian Hawkesworth. The authors would like to thank colleagues in the EU Committee of the Regions, in particular Bert Kuby, Andrea Forti and Pawel Zamojski for their support in organising the joint OECD-CoR survey and for their comments on the draft. Finally, authors are grateful to the team in the Hertie School of Governance, in particular Regina List, for comments on an initial version which was published in the 2016 Governance Report of the Hertie School of Governance. The opinions expressed in this paper are the sole responsibility of the author(s) and do not necessarily reflect those of the OECD or the governments of its member countries.
} 


\section{TABLE OF CONTENTS}

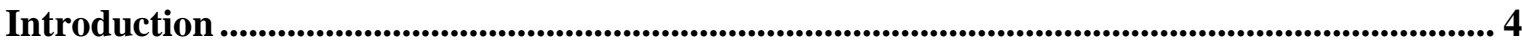

Decline in subnational investment and limited diversification in financing .............................. 4

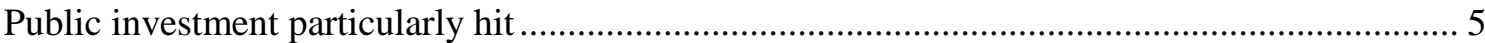

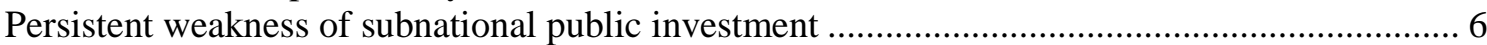

Which sectors have been more strongly hit by the decline of subnational public investment? ..... 8

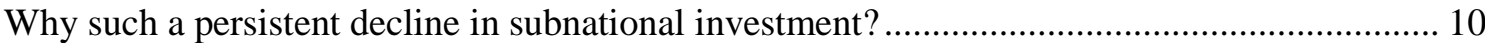

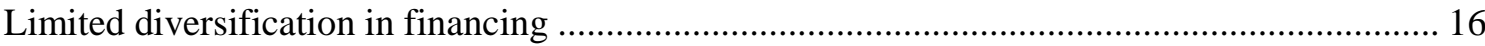

Responding to the challenges: Measures to stimulate subnational investment ........................... 18

Addressing governance challenges specific to SNGs: Implications and recommendations.... 20

Designing and planning infrastructure using a long-term perspective ..................................... 22

Coordinating across levels of government, jurisdictions, and infrastructure sectors................... 23

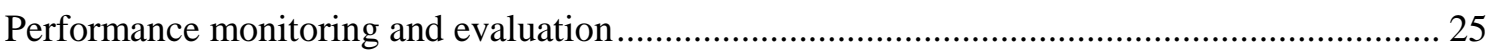

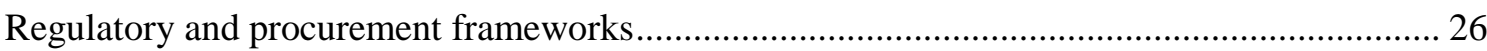

Improved subnational governance of infrastructure is connected to better outcomes ............ 27

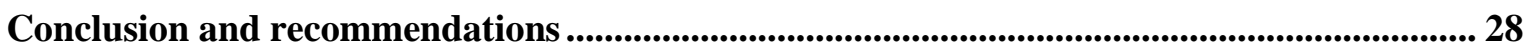

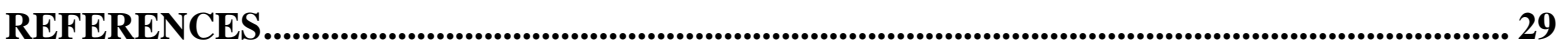

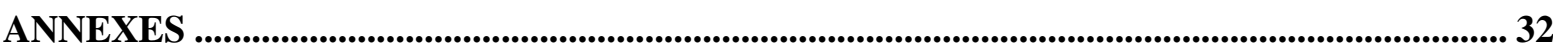

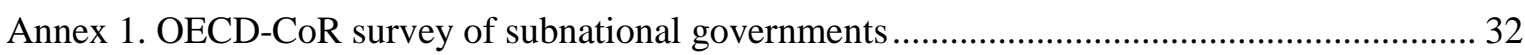

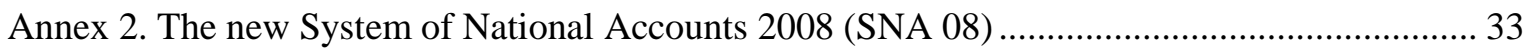

Annex 3. Consolidation plans affecting public investment over 2011-2015 .................................. 34

Annex 4. Methodology to elaborate governance indicators out of survey results............................. 35 


\section{Introduction}

Public investment is one of the fiscal tools with the strongest impact on growth in the short and the long term (IMF, 2015; OECD, 2016, Fournier and Johansson, 2016). Over the long term, the growth benefits of public investment can be larger in countries with an initially low stock of public capital, as the needs for public investment are larger. Recent estimates based on a baseline convergence model ${ }^{1}$ suggest that the growth effect of additional public investment would be substantial and positive in OECD countries given the existent capital stock, except in Japan (Fournier, 2016).

In many OECD countries, and particularly in Europe, private and public investment levels are down compared to the period prior to the 2008 global financial crisis. At the same time, the global challenges of climate change and population growth put strong pressure on the need for renewed infrastructure. Developed countries also face very high maintenance costs associated with existing infrastructure. For instance, in the US these maintenance costs are estimated to be one percentage point of GDP on an annual basis (Standard and Poor's, 2014). In developing countries experiencing strong demographic growth, there is a pressing need to build new infrastructure, in particular for public transport and housing. Assuming that public budgets will remain tight for some time to come, governments need to diversify their sources of financing of infrastructure investment.

Beyond the sheer volume of investment spending, the governance of subnational investment is essential to quality infrastructure investment. Infrastructure projects with deficient governance result in cost overruns, delays, underperformance, accelerated deterioration due to poor maintenance, and occasionally, expensive "white elephants" and "bridges-to-nowhere". Several recent studies estimate that improvement in infrastructure management could lead to substantial savings and enhanced infrastructure productivity (OECD 2015c, OECD 2013; IMF 2015; WB 2014; McKinsey 2013). National governments have an important role to play in establishing the framework conditions needed to better select and implement sound infrastructure projects (OECD 2015c). Subnational governments (SNGs) also play a key role, although this is often neglected in the literature linked to infrastructure. SNGs - defined as all levels of government (regional and local) ${ }^{2}$ below the national one, i.e. administrative regions, states/provinces, counties, and municipalities-are responsible for a large share of public investment: on average, around 60\% in the OECD. Most of this public investment goes to infrastructure. This particular role of SNGs poses specific challenges for both the financing and governance of infrastructure investment, as SNGs are inherently fragmented and diverse in their management capacities and resources.

Based on a 2015 survey of 255 subnational governments in the EU (hereafter, the OECD-CoR survey, see Annex 1), this paper explores specific challenges that subnational governments encounter in financing and managing infrastructure investment, and possible ways to improve the quality of governance surrounding subnational investments. This paper is organised as follows: the first section highlights the decline in subnational investment and some of its main reasons, building upon data from the national accounts as well as OECD-CoR survey results. The second section zooms in on the critical governance challenges that are more specific to subnational governments, and the governance practices perceived by SNGs to be helpful in overcoming some of these challenges. Finally, the last section gives a few insights on the links between the effectiveness of infrastructure investment governance and investment outcomes in selected EU regions and concludes with a set of recommendations to SNGs and national governments.

\section{Decline in subnational investment and limited diversification in financing}

Total investment (public and private) in OECD countries represented on average around 20\% of GDP in 2015. After having been relatively stable in the OECD from the mid-1990s to the mid-2000s, public and private investment suffered an important contraction following the 2008 financial crisis and the initial counter-cyclical increase in public investment (Figure 1). Corporate investment 
declined much more rapidly than output during the 2008 crisis and has weakly recovered since then, slowing down following the intensification of the European debt crisis in 2011 (Lewis et. al. 2014). In some European countries strongly hit by the crisis such as Portugal or Greece, total investment dropped to 15\% (Portugal) or even 12\% of GDP (Greece) in 2015. This sharp decline in corporate and household investment (i.e. private investment) damaged the real economy in the short term and can also reduce the productive capacity in the long term.

\section{Figure 1. Percentage of change in public and private investment in OECD countries between 2001 and 2015}

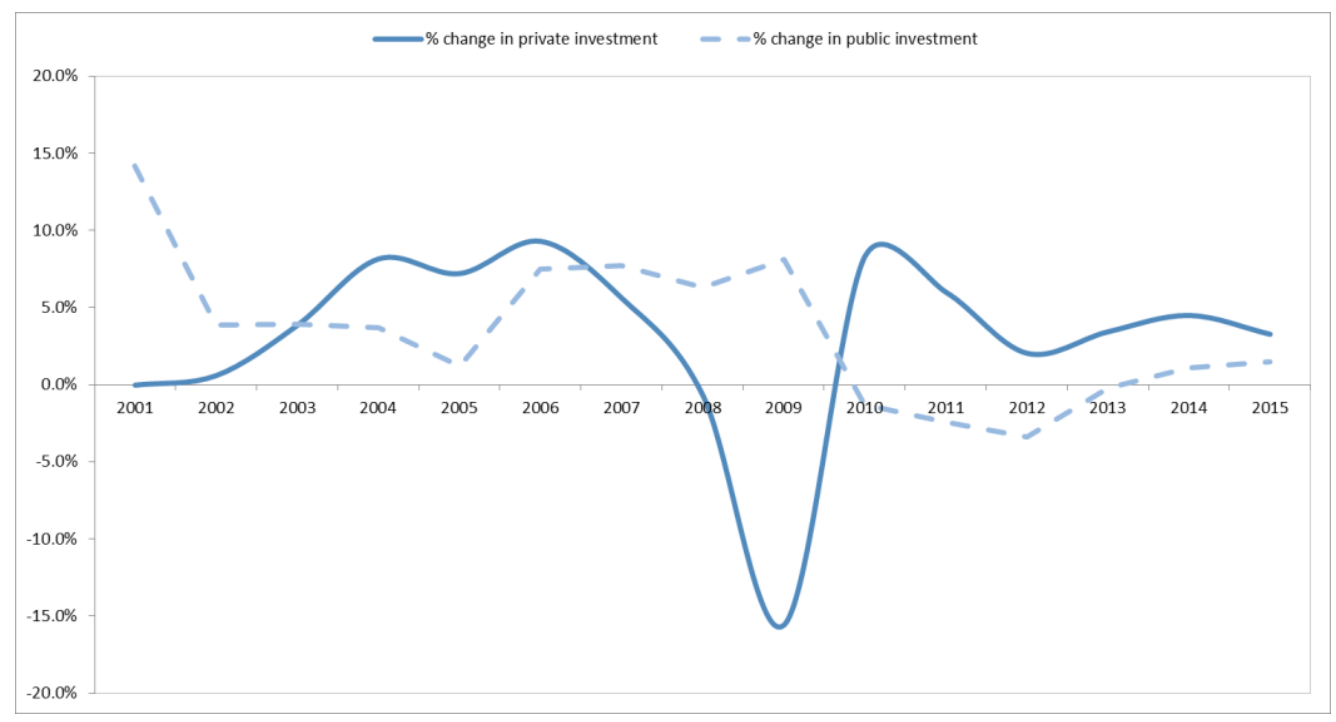

Source: OECD National Accounts database, available at: http://dotstat.oecd.org/?lang=en\# (accessed 10 July 2017).

\section{Public investment particularly hit}

Since the 1980s, public investment progressively declined in OECD countries from $4.5 \%$ of GDP on average in 1980 to $3 \%$ in 2014. The long-run downward trend is due to the fact that many OECD countries have well-developed infrastructure and focus mainly on operation and maintenance. This also reflects a change in investment from infrastructure to intangibles. Moreover, Public-private partnerships (PPPs) are also not necessarily counted as public investment ${ }^{3}$.

Public investment rose before and during the economic crisis of 2008-2009 (thanks partly to a counter-cyclical increase in public investment), but declined to historically low levels after 2010 (Figure 2). In many OECD countries the share of total and public investment in GDP has not yet reached the pre-crisis levels; in some countries public investment remains half of what it was before the crisis. In 2015, public investment represented around 50\% of its 2007 level in Spain and Ireland, and around $70 \%$ in Greece, Latvia and Portugal. In contrast, investment spending had increased by more than $40 \%$ over the same period in Denmark, Luxembourg, Mexico, Norway and the Slovak Republic.

The decline in public investment has been particularly important in European countries. Public investment in the European Union has been particularly affected by austerity packages introduced by several countries in an effort to reduce their levels of sovereign debt. The level of investment in this region of the world is estimated at EUR 430 billion less than in 2007 (OECD, 2015) and significantly less than during the two past decades. In 2013, public investment-to-GDP gaps compared to pre-crisis levels are especially large in countries strongly affected by the crisis, amounting to more than $3 \%$ of GDP in Ireland, more than 2\% of GDP in Spain, and more than $1 \%$ of GDP in Czech Republic, Greece, Iceland and Portugal. 


\section{Persistent weakness of subnational public investment}

\section{Subnational governments play a strong role in subnational investment spending}

Public investment is a shared responsibility across levels of government. Subnational governments are key actors in public investment. In 2015, they represented on average $59.3 \%$ of total public investment in the OECD and 3.1\% of GDP (Figure 2). On average, in unitary countries this ratio reaches $52.5 \%$ of public investment (OECD 26 on Figure 2). The ratio of subnational to national spending tends to be higher in most federal countries (OECD 9 on Figure 2), where it combines investments by the states and by local governments. Variations across countries are large here as well, as SNGs represent as little as $12 \%$ of public investment in Chile, and up to $92.8 \%$ in Canada.

Figure 2. Share of public investment in GDP and share of SNGs in public investment in OECD countries (2015)

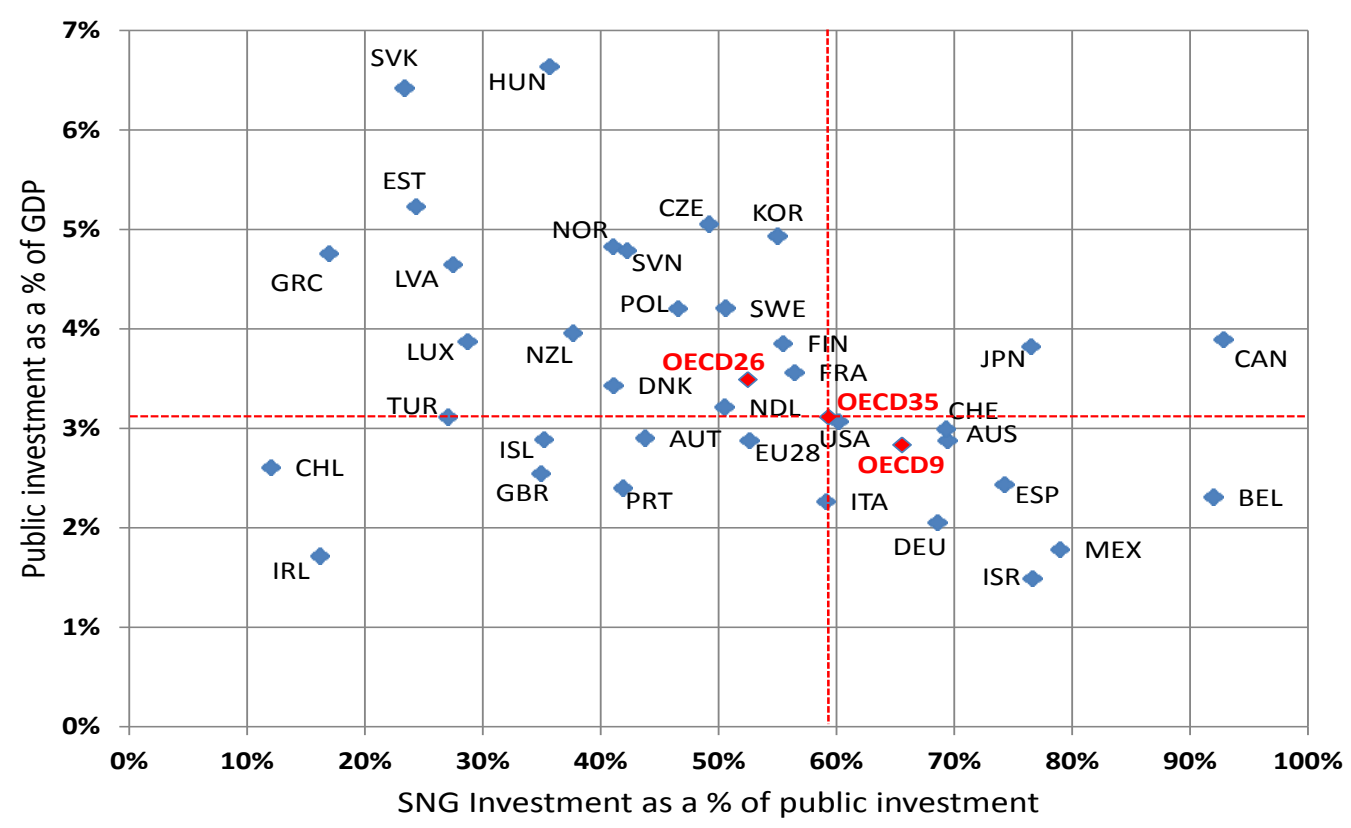

Note: OECD 26: Unitary countries; OECD 9: Federations \& quasi-federations; OECD 35: All OECD.

Source: OECD (2017), Subnational governments in OECD countries: Key data (brochure), OECD, Paris, www.oecd.org/regional/regional-policy and database: http://dx.doi.org/10.1787/region-data-en.

A large share of subnational public investment, measured by gross fixed capital formation (GFCF), goes to infrastructure in areas of critical importance for future economic growth, sustainable development and citizen well-being. In terms of total investment by subnational governments across the OECD, 39.2\% is allocated to economic affairs, accounting for $0.73 \%$ of GDP in 2014. Inside economic affairs, the single most important item by far is transport. Approximately $22 \%$ of public investment is used for investment in the education sector, a further $9 \%$ is dedicated to general public services (construction and improvement of public buildings) and almost 9\% to housing and community amenities (community development, water supply, street lighting, etc.). The remaining investment is allocated to environmental protection, healthcare, and defence.

\section{Subnational public investment: An adjustment variable, with great variation across $S N G s$}

The decline of public investment was particularly acute at the subnational level, as subnational public investment has been used as an adjustment variable in many OECD countries after 2010 (OECD, 2013). Among OECD countries, the decline in subnational public investment has been 
particularly marked in the EU (Figure 4). In the European Union, public investment conducted by SNGs decreased by almost $18 \%$ between 2009 and 2014 (i.e. 5\% per year in real terms). While in 2014 public investment at the central government level seemed to be slightly recovering in the EU, public investment at the subnational level still declined (Figure 3). After a slight increase of subnational public investment in the EU in 2015, it has strongly declined again in 2016 at the national and subnational levels in the EI $(-9.9 \%$ in the EU in real terms, $-14 \%$ in Italy, $-24 \%$ in Spain for example).

Figure 3. Central and subnational government investment trends in OECD and EU countries over 20052014 (Base $100=2006)$

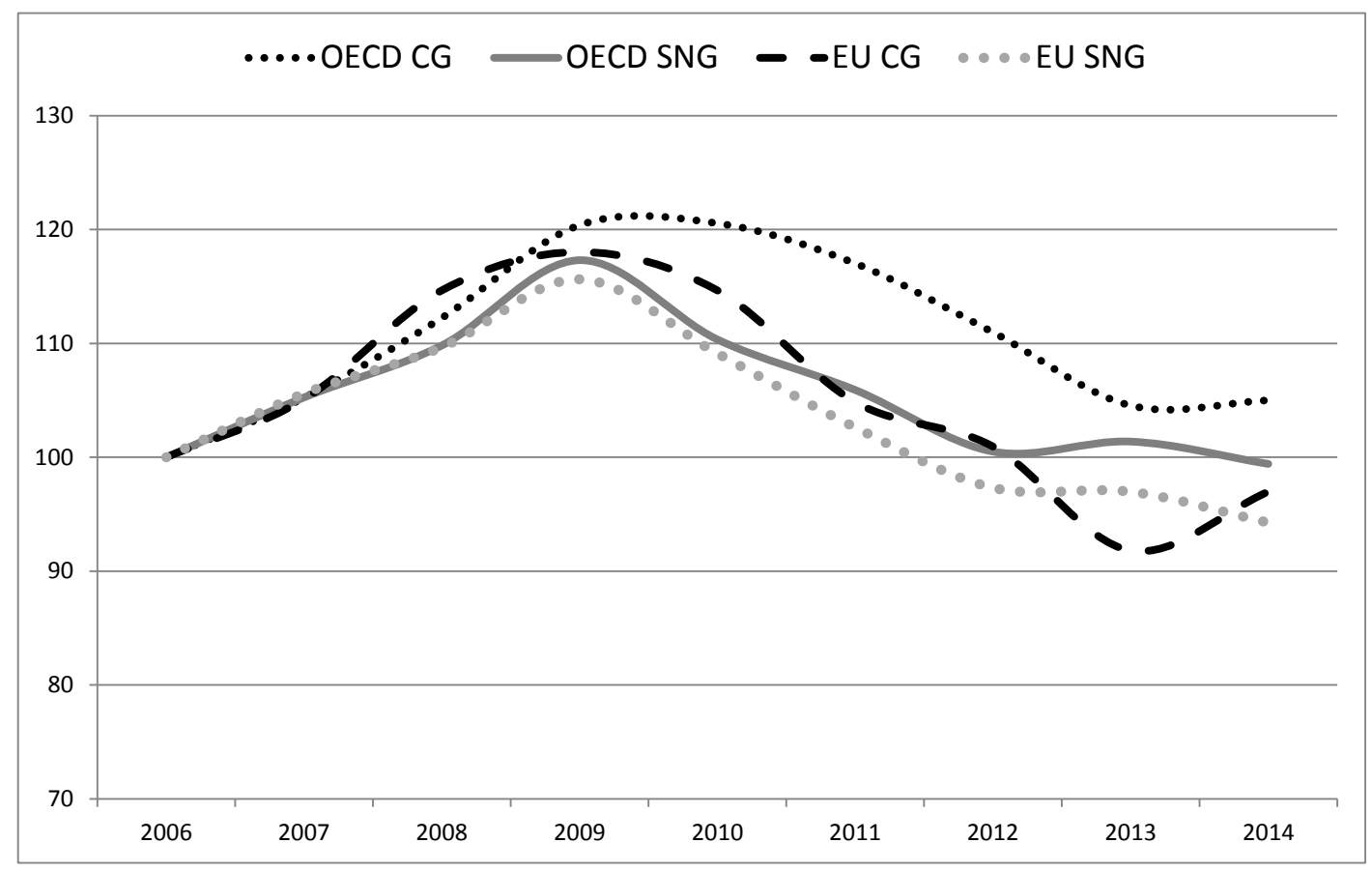

Notes: $\mathrm{CG}=$ Central Government; SNG=Subnational Government. All OECD countries except Chile, Iceland and Slovenia. Australia, Israel, Japan, Mexico, New Zealand, Switzerland and the US: 2013 instead of 2014. Mexico: 2003 instead of 2000-2002. Greece: 2006 instead of 2000-2005. Turkey: 2006 instead of 2000-2005 and 2011 instead of 2012-2014. Data from SNA 08.

Source: OECD elaboration based on OECD National Accounts.

The decline in subnational investment has varied significantly across countries and sometimes across regions of a single country.4 For example, in Spain, after the introduction of budgetary consolidation packages, subnational investment has significantly dropped compared to its pre-crisis level in all of the autonomous communities (ACs). In 2016, AC subnational investments accounted for $45 \%$ of its 2008 level, but the Basque country managed to keep its investment at $63 \%$ of 2008 level in 2016, while in Castilla-La Mancha capital expenditure accounted for less than a third of 2008 level.

The results from the 2015 OECD-CoR survey show a great variation across the different categories of SNGs in the EU. Most of the cuts in public investment are reported by large SNGs such as regions, counties and inter-municipal cooperation bodies (usually found in large urban agglomerations). By contrast, only $31 \%$ of small municipalities (below 50000 inhabitants) and 25\% of larger municipalities report having decreased their spending by more than $10 \%$ since 2010 (Figure 4). Since large SNGs typically devote a higher share of their overall expenditures to investment, this might indicate that the cuts were made to large-scale projects, such as strategic infrastructure investment. 
Figure 4. Share of SNGs reporting a substantial (10\% and more) decrease of subnational investment since 2010

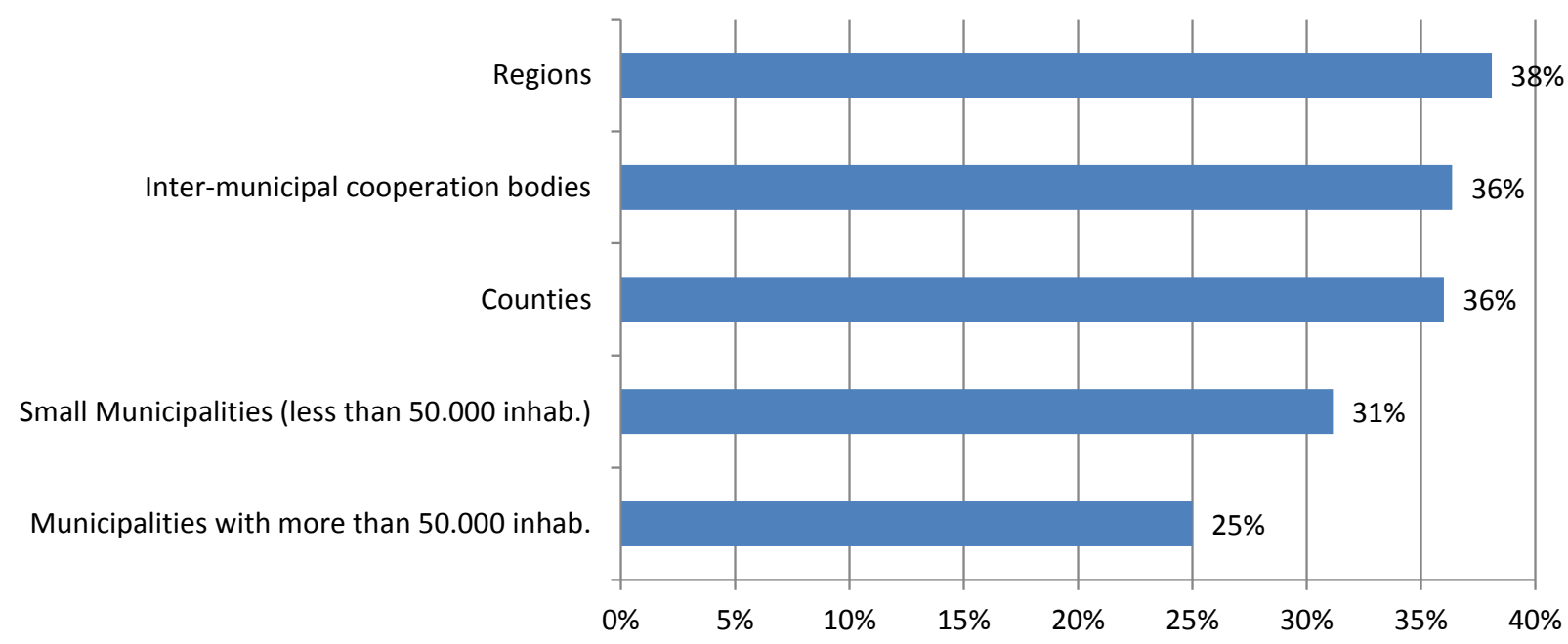

Source: Results of the OECD-CoR survey of subnational governments in the European Union (2015).

Which sectors have been more strongly hit by the decline of subnational public investment?

Housing, recreation and culture spending are strongly affected and health keeps increasing

Although all categories have been affected by the decline in investment in the EU since 2010, there are large variations across sectors (Figure 5). Despite investment cuts in all other sectors, SNG investment in health rose by $40 \%$ between 2010 and 2015. This might be a consequence of population ageing and the structural trend of increasing health spending in most OECD countries. SNG investment also registered a modest increase in social protection expenditures, as many SNGs had to face a sharp increase in poverty and unemployment, particularly in Spain, Portugal and Greece. Economic affairs (the most important component of which is transport infrastructure), the largest sector for SNG investments, has been largely spared by investment cuts: capital expenditures are almost stable in real terms. The same is true for education expenditures. By contrast, investment in sectors such as housing and community amenities and recreation, culture and religion are down by $20 \%$ and more. 
Figure 5. Trends in subnational public investment in EU countries, over 2006-2015 (base $100=2006$ )

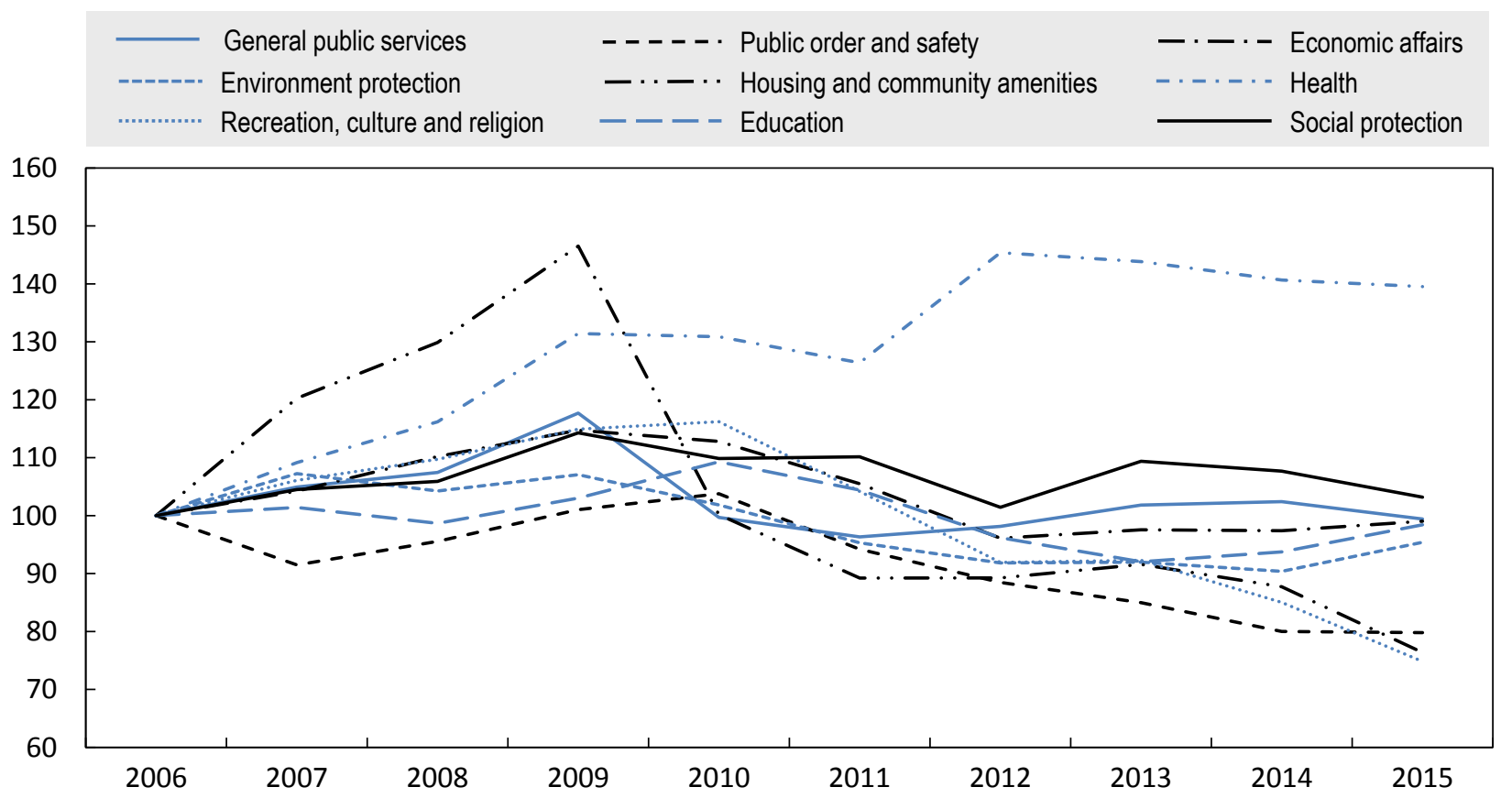

Source: OECD elaboration based on Eurostat data (2015), General government expenditure by function (COFOG).

There are of course strong variations in subnational investment trends across EU countries. For instance, SNG health investments rose substantially in Central Europe, Scandinavian countries and France after 2008. Spain is the only country that experienced a sharp fall in subnational health expenditures after 2008. SNG transport investments, which account for most of investments in economic affairs, declined sharply in Ireland, Greece, Italy and Lithuania after 2011. By contrast, transport investment by SNGs has been rising in Scandinavian countries and in many of the Central European countries that benefited from EU Structural and cohesion funds (e.g. Bulgaria and Hungary). Beyond government priorities and the availability of funding (including from EU Funds in Central Europe), rising subnational investments can reflect decentralisation reforms: between 2007 and 2015, this was the case in Denmark as well as some countries of Central Europe (e.g. Poland, Slovak Republic, and Slovenia), for instance (OECD, 2017).

Spain experienced a sharp fall in SNG transport investments, dropping by almost $70 \%$ between 2010 and 2014.5 It should be noted that the Spanish case is specific because of a very pro-cyclical pattern of subnational investment (De la Fuente, 2017) and some evidence of overinvestment in public transport infrastructure during the 2000s (Albalate, Bel and Fageda, 2015). For instance, in a 2014 special report, the European Court of Auditors highlights several investment projects in Spanish airports in the early 2000sand judges that in several cases, such as in Fuerteventura or Cordoba, the expansion of terminals resulted in overcapacity. Due to low air traffic, the economic benefits to the regional economy of these investments are very limited (European Court of Auditors, 2014). This is a reminder that efficient public investment requires high quality design and planning capacity (see page 21).

The results of the OECD-CoR survey shows that almost all SNGs surveyed report gaps in public investment spending, i.e. insufficient resources to finance infrastructure needs. The types of gaps, shown in Figure 6, vary greatly across the different categories of infrastructure and reflect the allocation of competencies across levels of government. Road (transport), which represents around three-quarters of economic affairs investment, is the most impacted category, particularly for small 
municipalities (85\%). On the contrary, gaps in infrastructure for education and for public transport are mostly mentioned by large SNGs (i.e., large cities and regions).

Figure 6. Sectors most affected by funding gaps in SNGs)

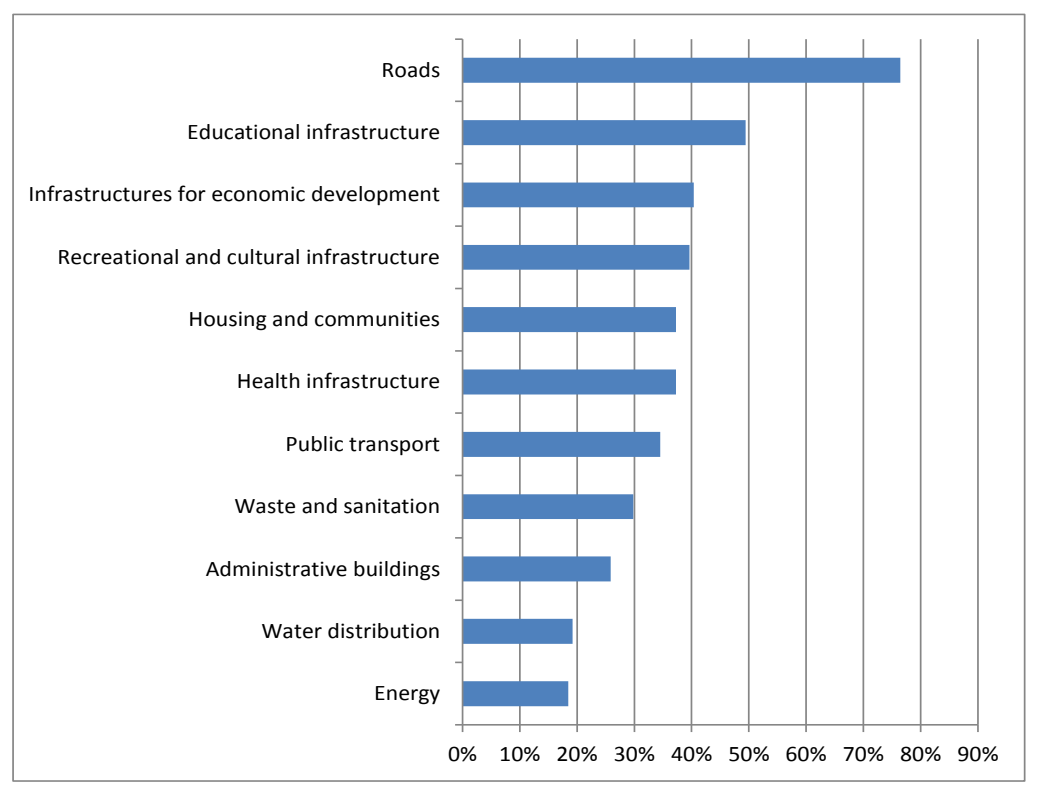

Source: Results of the OECD-EU survey of subnational governments in the European Union (2015).

\section{Why such a persistent decline in subnational investment?}

After 2010, fiscal consolidation policies adopted at the national level led to a sharp decline in subnational investment. In many OECD countries, subnational current expenditures (and in particular social benefits) have grown more rapidly than subnational revenues, thereby reducing the fiscal space left for investment (OECD, 2014). Current expenditures are indeed more difficult to cut (political cost to cut subsidies or transfers, stickiness of the wage bill) (Bloch and Fournier, forthcoming). The case of Spain is a good illustration: Spanish regions (autonomous communities) made an impressive downward adjustment in subnational investment to preserve other subnational expenditure items in the midst of the economic crisis (Box 1). 


\section{Box 1. The crowding out of public investment by rising debt service and current spending: Autonomous}

Communities in Spain

After Ireland, Spain is the EU country with the sharpest decrease in public investment after the 2008 global financial crisis. Public investment decreased by $48 \%$ between 2008 and 2015 (in current prices). Spain is very decentralised in terms of public finance, with subnational governments accounting for $74 \%$ of public investment. Indeed, subnational governments and particularly Spain's autonomous communities (regional governments) sharply reduced public investment between 2010 and 2014, with the bulk of the adjustment occurring between 2011-2012, when Spain was caught into the European debt crisis.

Figure 7. Evolution of public investments - autonomous communities* (Index: 2005=100)

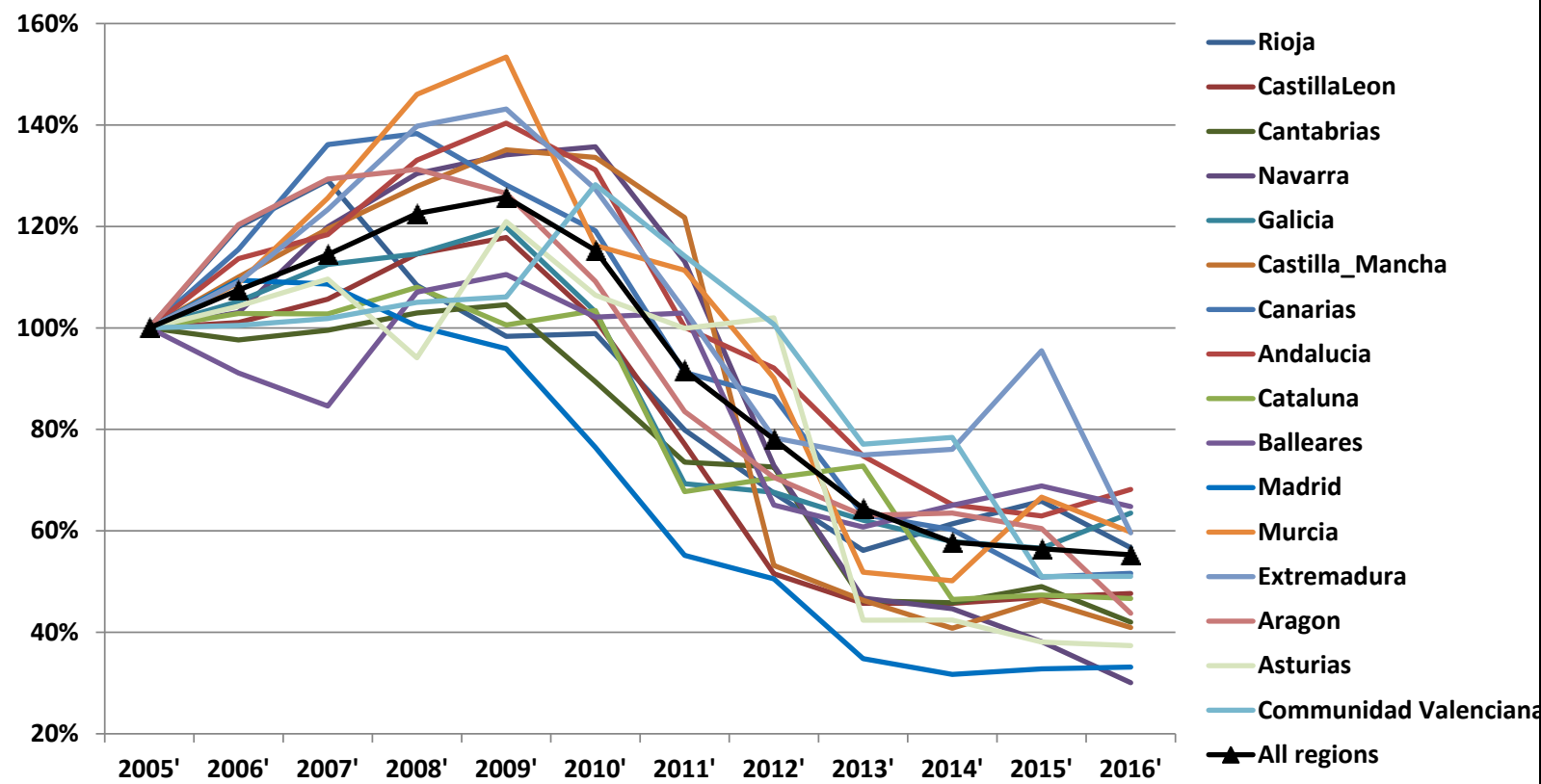

* Except the Basque country.

Source: Ministerio de Hacienda y administraciones publicas, Database «Presupuestos de las CC.AA. », available at: http://serviciostelematicosext.minhap.gob.es/SGCAL/PublicacionPresupuestos/aspx/inicio.aspx (accessed on 4 July 2017). Deflated using the deflator for GFCF in Spain from the OECD National Accounts database.

De la Fuente (2017) highlights that public investment by autonomous communities (AC) has been very procyclical, with rapid growth during the expansionary period of the 2000's and deep cuts during the first years of the crisis (beginning in 2009). Between 2009 and 2013, AC experienced unprecedented fiscal deficits which translated into a rising debt level, and hence a greater share of revenues had to be allocated to debt repayment. Confronted with declining tax revenues and a rising debt service burden (increasing volumes of debt were compounded by high interest rates), AC cut their capital expenditures heavily while safeguarding current expenditures (net of interests) such as staff payroll or social transfers and services. After 2013, current expenditures (net of interests) started to increase again, reaching, in 2016, the pre-crisis level of 2008. By contrast, AC investments in 2016 amounted to slightly less than half of their 2008 level (De la Fuente, 2017).

The sharp decrease in public investments after 2009 was universal among Spanish ACs, with variations across regions. The Basque country stands out because it registered a lower and more gradual decline of public investment (unlike almost all other regions), after a very pronounced boom between 2006 and 2009. The Basque country had lower fiscal deficits than most other regions during the recession years of 2009 and 2011-2013, and started the crisis with the lowest debt level among all AC (its debt amounted to only $2 \%$ of regional GDP in 2005). Therefore, it is fair to assume that its solid financial situation allowed the Basque country to maintain some of its public investments during the crisis. 


\section{Box 1. The crowding out of public investment by rising debt service and current spending: Autonomous Communities in Spain (continued)}

Figure 8. Evolution of public investments in Spain - Basque country vs. national trend (Index: 2005=100)

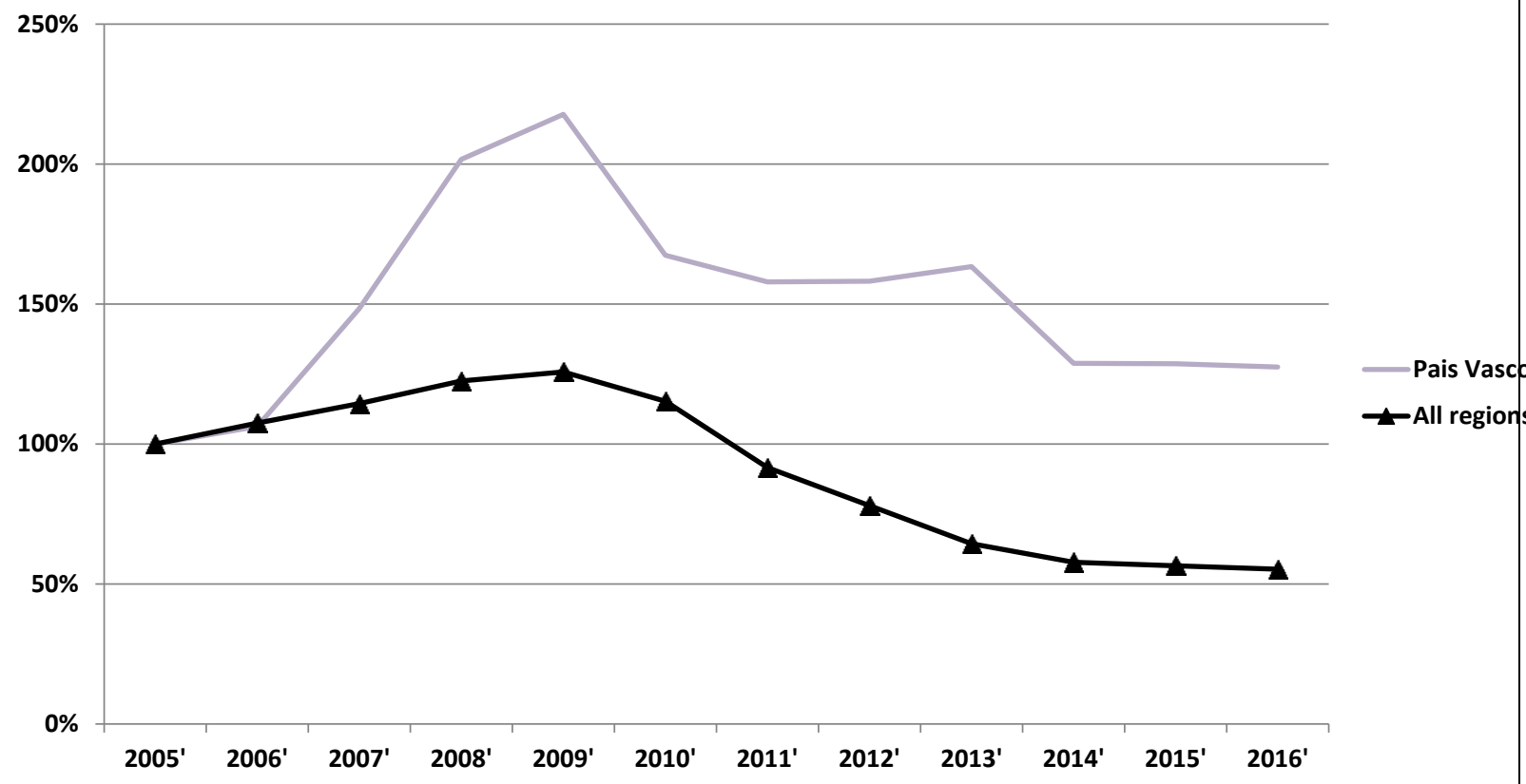

Source: Ministerio de Hacienda y Administraciones Públicas, Database «Presupuestos de las CC.AA. », available at: http://serviciostelematicosext.minhap.gob.es/SGCAL/PublicacionPresupuestos/aspx/inicio.aspx (accessed on 4 July 2017). Deflated using the deflator for GFCF in Spain from the OECD National Accounts database.

If the Basque country is excluded, there is some correlation (Pearson coefficient $37.5 \%$ ) between AC debt service burden (as a share of total expenditures) during 2005-2016 and the relative cut of AC public investments (compared to its 2008 level). This confirms that many AC cut their capital expenditures to make room for a higher debt service burden. However, the three AC that experienced the sharpest cuts in capital expenditure (Navarra, Madrid and Asturias) are among the ACs with the lowest debt level and low or moderate debt service burden. This suggests that, to some extent, these ACs could have chosen to cut capital expenditures rather than running larger budgetary deficits (and therefore accumulate debt). This could be the case of Madrid, which combines the lowest debt level among ACs (14.2\% of regional GDP in 2015) and the harshest cuts on capital expenditures (2016 capital spending accounted for $33 \%$ of its 2005 level).

Sources: Angel de la Fuente (2017), Las finanzas autonomicas en 2016 y entre 2003 y 2016, BBVA Research Working Paper, Available at (in Spanish): https://www.bbvaresearch.com/wp-content/uploads/2017/05/Finanzas aut WP.pdf; Ministerio de Hacienda y Administraciones Públicas, Database « Presupuestos de las CC.AA.».

\section{Reduced fiscal space for investments}

Many consolidation programs envision or explicitly mention the amounts to be saved by reducing public investment. Although they may not be fully implemented, they still show that investments are considered a privileged adjustment variable in many OECD countries (Annex 3, Table 1). The economic literature has established that during budgetary consolidation episodes, countries tend to cut investment more heavily than current expenditures or wages (Blöchliger et al (2012), Blanchard and Giavazzi (2003)). A study by the European Commission (2007) finds that most cuts are implemented in economic affairs (which include a large share of gross capital formation and capital transfers) rather than in other categories of spending such as social protection, health or 
education. Indeed, in such categories of spending, cuts may be highly unpopular and politically costly; hence officials may prefer to cut investments instead.

Even if the decrease of SNG revenues is not the main reason behind the recent decline of SNG investments throughout the EU, the dynamics of subnational revenues played a role in the reduced fiscal space available to SNGs for investment. For instance, total public revenues in real terms were still below their pre-crisis level in Greece, Iceland, New Zealand, Norway, Spain, and the UK. In these countries, it is mostly a decline in transfers to SNGs that explains the decrease in subnational revenues. On average, transfers to SNGs were cut by $2.4 \%$ per year (in volume) between 2009 and 2013 in EU countries. The sharpest cuts over the period were seen in Ireland, Spain, Italy, Czech Republic and the United Kingdom (-3\% per year) (Figure 9). Taxes are the other major component of SNG revenues. Although they have recovered in a large majority of OECD countries, in some countries SNG budgets are still struggling with lower levels of taxes (e.g., Estonia, Iceland, Italy, Luxembourg, Spain and the UK). However, it is important to remember that a.

Figure 9. Change in grants and subsidies revenue of SNGs in EU countries between 2009 and 2013 (\% annual average change in real terms)

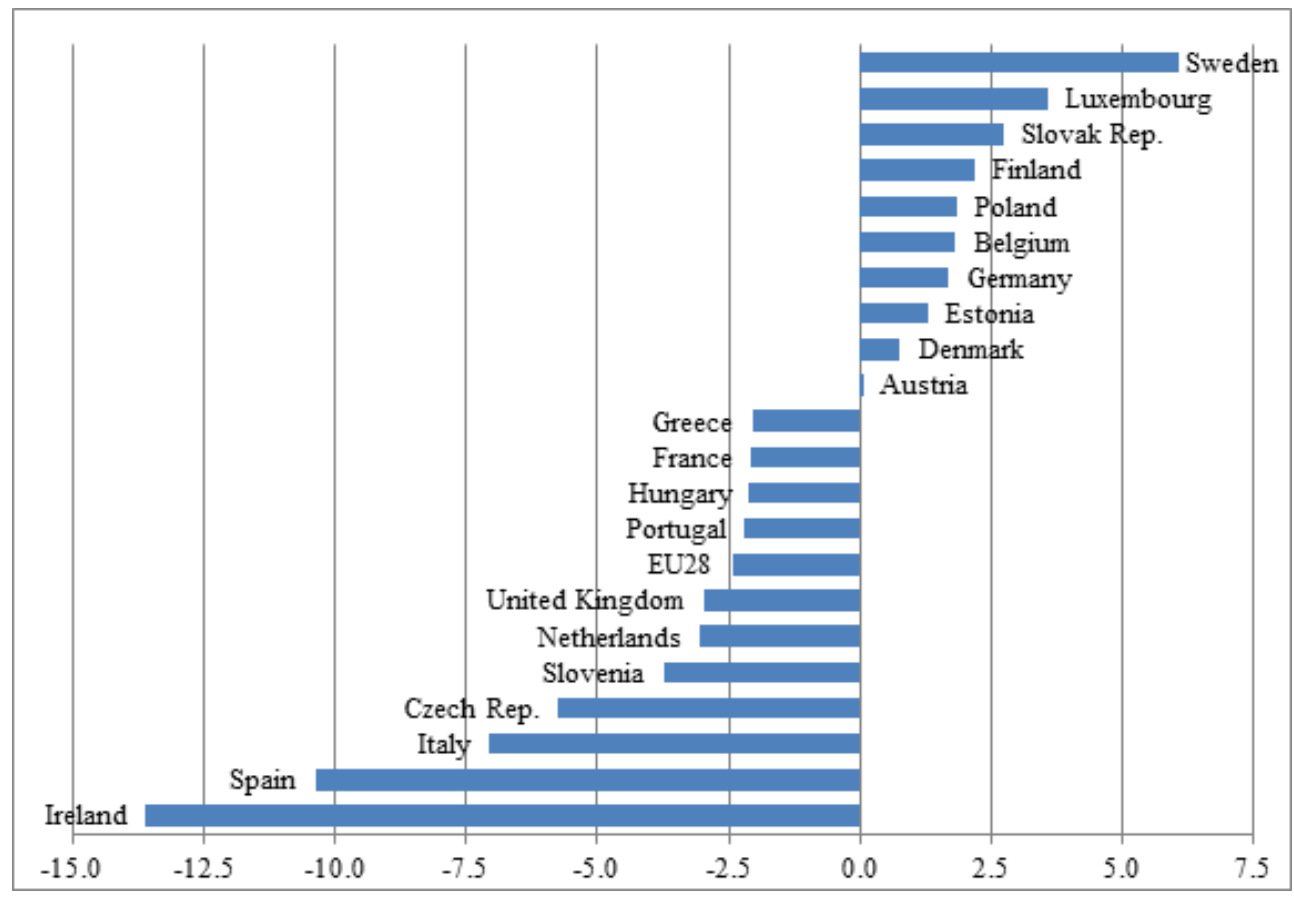

Source: OECD elaboration based on OECD National Accounts data base, http://dx.doi.org/10.1787/region-data-en.

As subnational revenues proved to be quite resilient during the crisis, the main explanation for the decreased resources available for investment comes from the expenditure side. On average, subnational revenues grew at a slower pace than expenditures since the beginning of the crisis. The fastest-growing type of SNG expenditure is, by far, social benefits - which grows much faster than GDP (Figure 10). Since 2009, public employee wages have, on average, stagnated. However, intermediate consumption has increased faster than revenues (16\% in real terms since 2006); and the growth rate for social benefits has attained $27 \%$ on average, partly because of unemployment. This increase in current expenditure has further reduced the fiscal space available for SNGs to invest. 


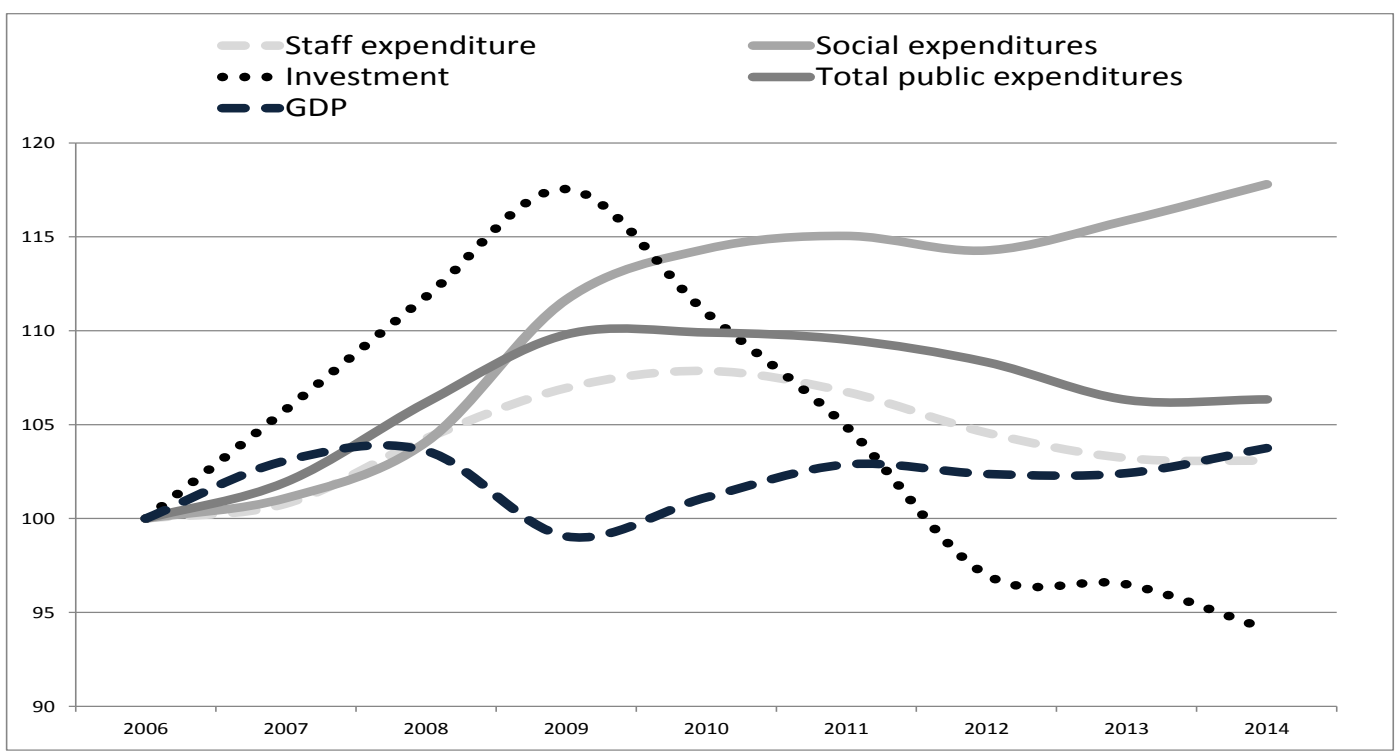

Note: All OECD countries except Australia and Chile. Turkey: 2011 instead of 2012 and 2013.

Source: OECD National Accounts (data extracted in 2015).

\section{Introduction of expenditure ceilings in some OECD countries}

Fiscal framework reforms such as expenditure ceilings and fiscal rules contributed to reduce the fiscal space for SNG investment. Several countries, such as Denmark, Finland, Spain or Australia introduced expenditure ceilings: if such ceilings apply to investments as well, capital expenditures are likely to be targeted in priority to meet the rule criteria. For instance, in 2010 Austria's Internal Stability Pact limited nominal expenditure growth of all levels of government to the estimated growth of potential GDP. In Spain, the 2012 Organic Law on Budgetary Stability and Financial Sustainability introduced a new expenditure ceiling for autonomous communities: nominal expenditure growth should not exceed medium-term GDP growth.

SNG debt still remains relatively low compared to total public debt in the OECD (20\% of public debt and $24.4 \%$ of GDP on average in 2015). Securities have been the fastest-growing category in SNG debt, even though a large share of OECD countries does not rely on them at all. This may be explained by the fact that, over the past years, SNGs have faced greater difficulty in accessing credit from financial institutions. The OECD-CoR survey results reveal that subnational borrowing has been increasingly out of reach for many SNGs in the EU. 39\% of SNGs mention a reduction or stabilization in borrowing to finance investment since 2010 , with only $12 \%$ reporting an increase. Only $4 \%$ of SNGs have increased their recourse to bonds, a finding that is not very surprising since SNG recourse to bond financing is not permitted in many EU countries, especially for municipalities (Figure 10).

Moreover, the recent evolution of SNG fiscal rules is likely to limit the increase of subnational debt. Many countries have introduced balanced budget requirements that may affect expenditure, or debt-break provisions which do not include exemptions for funding investment expenses (Box 2). 


\section{Box 2. Reforms of fiscal rules affecting SNGs}

\section{Budget balance rules}

In spring 2012, Austria adopted an Internal Stability Pact that came into force in December 2012. This pact sets new fiscal rules applicable to all levels of government. Concerning deficits, all levels of government must reach a balanced budget in 2016. From 2017 onwards a structural balance rule will be implemented, relating deficits to the output gap. The general government cycle will be used in order to calculate SNG structural budget requirements (which target will represent $2 / 9^{\text {th }}$ of the total cyclical effect, the other $7 / 9^{\text {th }}$ being allocated to the CG). Asymmetric SNG shocks are not considered a problem since SNG revenues have little cyclicality: tax sharing apportionment formulas between central authorities and the Lander rely mostly on population (hence are relatively non-cyclical), and local authorities are mainly financed through less-cyclical taxes based on real estate. The new rules also include a debt criterion. All levels of government must reduce their level of debt by $1 / 20$ per year.

In Belgium, the Cooperation Agreement reached in December 2013 between the federal government, communities and regions for implementing the Treaty on Stability, Coordination and Governance requires the general government budget to be balanced; individual targets in nominal and structural terms for central and local authorities will be defined.

In Denmark, the Budget Law approved in 2012 introduces a balanced budget rule: structural deficits (on a yearly basis) should not exceed $0.5 \%$ of GDP.

In 2009, Germany introduced a "debt brake" in its Constitution (Grundgesetz) to ensure that subnational budgets are financed without any structural deficits from 2020 onwards, with only a small structural deficit allowed for the federal budget $(0.35 \%$ of GDP). In addition, a new instrument, the Stability Council, was instituted to survey all public budgets on an annual basis using common benchmarks, to monitor public borrowing and to co-ordinate medium-term financial planning in a multi-level government context.

In Italy, the Domestic Stability Pact introduced a budget balance rule for municipalities and provinces. The Stability Law for 2014-2016 eases the budget constraints for local governments to exclude capital account payments up to $€ 1$ billion and another $€ 500$ million to accelerate payment of past-due debts.

In Japan, the Fiscal Management Strategy introduced in 2010 includes numerical targets at the short, medium and long term to reduce the primary budget deficit of the central and local authorities.

In Mexico, the Federal Budgetary law (Ley Federal de Presupuesto y Responsabilidad Hacendaria), approved in late 2013, introduces a structural balance rule; a constitutional reform to limit state and municipal debt is still under consideration.

In the Netherlands, an agreement anticipating the entry into force of the Law on the Sustainability of Public Finances was reached in January 2013 with local authorities; a multi-annual budget balance path will be introduced for local governments. In 2013, a deficit limit of $0.5 \%$ of GDP was applied to local authorities as a whole.

In Poland, the Public Finance Act (2011) already stipulated to balance local current budgets. In 2014 new rules came into force for local authorities: the debt servicing-to-revenues ratio must remain smaller than the average ratio of current revenues (plus asset sales and operating expenditure)-to-total revenue over the last three years.

In Slovenia, the Parliament approved in 2013 a balanced budget amendment to the constitution that came into force in 2015 .

In Spain, an amendment to the constitution was adopted in 2011 to underpin the fiscal consolidation targets for all Spanish administrations, following the EU framework. The main feature of the reform was that neither the central government nor the autonomous communities were allowed to have deficits exceeding the maximum set by the EU, and local governments were required to balance their budgets. The maximum structural deficit should be set according to law as a percentage of GDP. This limit will only be in force from 2020 onward. The Organic Law on Budgetary Stability and Financial Sustainability (2012) introduces a structural balanced budget rule for all levels of governments from 2020 onwards. Debt reduction pathways will be revised in 2015 and 2018 to ensure that this objective is met. 


\section{Box 2. Reforms of fiscal rules affecting SNGs (continued)}

Restrictions on debt and debt service:

Restrictions on the level of debt:

- In Austria, a debt break was introduced for all levels of government in 2012.

- Poland: SNG debt should not exceed $60 \%$ of GDP;

- Portugal: two recent laws introduced new fiscal rules for SNGs. At the regional level, the law on the Finances of the Autonomous Regions stipulates that the autonomous regions' liabilities should not exceed 1.5 times their 3-year average net current revenue. At the municipal level, the law on Local Finances introduces similar requirements for each municipality individually (municipalities' liabilities should not exceed 1.5 times their 3-year average net current revenue).

Restrictions on debt service as a share of overall expenditures:

- Greece: debt repayments should not exceed $20 \%$ of regular revenues;

- Italian local governments: interest payments should not exceed $12 \%$ of current revenues;

- Italian regions: interest payments should not exceed $25 \%$ of revenues from taxes, transfers and property sales;

- Slovak Republic: loan instalments and interest should not exceed $25 \%$ of current revenues for the previous year.

Sources: Vammalle, C., R. Ahrend and C. Hulbert (2014), "A Subnational Perspective on Financing Investment for Growth II - Creating Fiscal Space for Public Investment: The Role of Institutions", OECD Regional Development Working Papers, No. 2014/06, OECD Publishing. OECD (2014), OECD Economic Surveys: Czech Republic 2014, OECD Publishing. OECD (2014), OECD Economic Surveys: Denmark 2013, OECD Publishing. OECD (2013), OECD Economic Surveys: Japan 2013, OECD Publishing. Stability Program 2014 (Belgium, Estonia, Italy, Netherlands), Convergence Program Poland (2014), National Reform Program Slovenia (2014). Hulbert, C. and C. Vammalle, "Ensuring fiscal sustainability of subnational government debts", forthcoming. OECD Network on Fiscal Relations across Levels of Government Survey on Subnational Fiscal Rules and Macroeconomic Management, September 2011, updated March 2015.

\section{Limited diversification in financing}

Given a decrease in 'traditional' sources of funding, diversification to external sources of financing would be needed to be able to invest in infrastructure. However, the survey results show that such diversification, through private funding, public-private partnerships (PPP), or funding through financial markets via inter-municipal borrowing agencies for instance, remains very limited at the subnational level. Only a minority of SNGs $(7 \%)$ report having increased private sources of financing for infrastructure investment since 2010 (Figure 11), essentially metropolitan areas and regions. Among the reasons that might explain this lack of interest in adding private sources of financing are the complexity of using PPPs and the extensive technical and legal capacities that they require, which most SNGs below a certain size do not have. It may also reflect a lack of knowledge within SNGs of the variety of financial mechanisms available, and a lack of coordination across SNGs to pool financial resources to engage in innovative financing mechanisms. 
Figure 11. Sources of financing in subnational governments

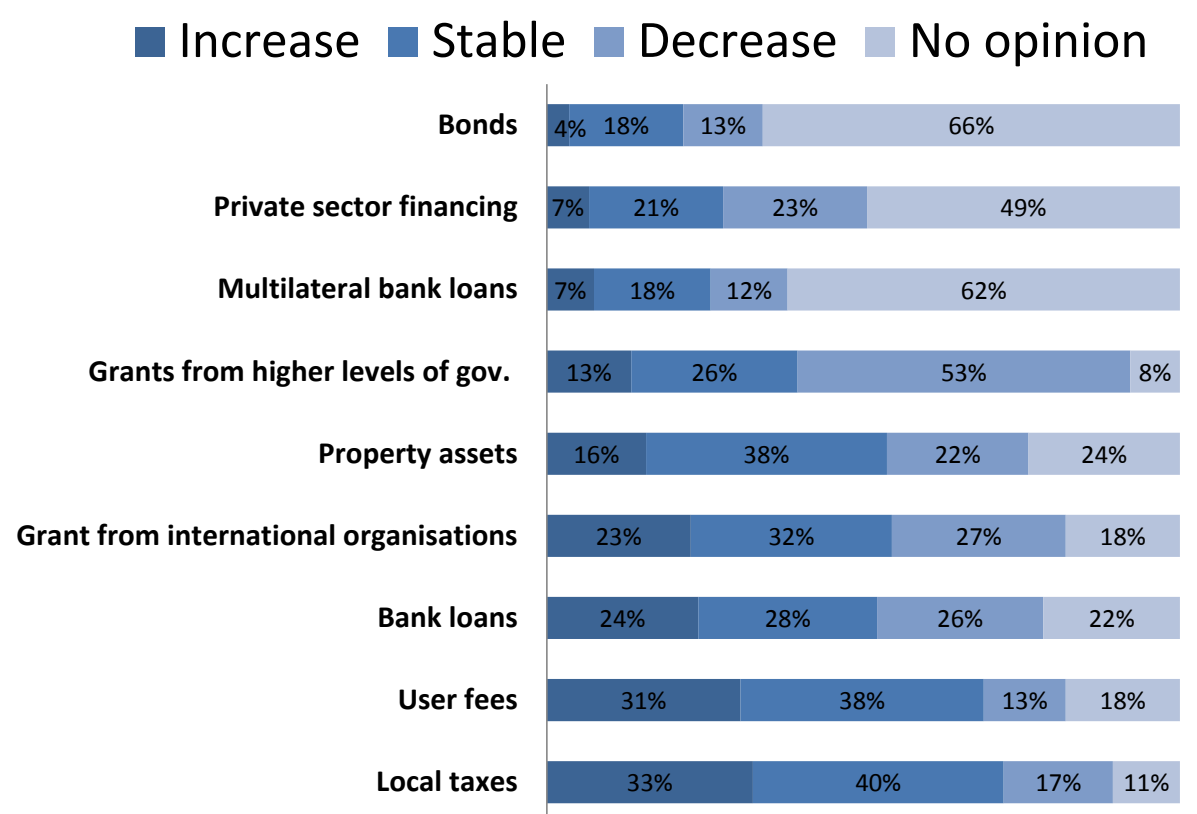

Source: Results of the OECD-CoR survey of subnational governments in the European Union (2015).

To be effective, PPPs have to be used with cautious as they largely depends on the capacity of SNGs to allocate risks efficiently between public and private parties in order to reduce project costs as well as ensure sufficient incentives. Moreover, PPPs have strong legal, appraisal and monitoring arrangements while some sectors require speed due to rapid technological changes (e.g. the IT and health sectors). Therefore, the advantages of PPPs vary significantly across projects and SNGs (Schwartz and al., 2008; Engel and al., 2014) and small municipalities need support from central governments. The Canadian government assists SNGs in their management of PPP projects through its PPP Canada agency, which provides both technical expertise and support and, in some cases, cofinancing (Box 3). 


\section{Box 3. Example of PPPs Canada}

Public-private partnerships (PPPs) are a long-term, performance-based approach to procuring public infrastructure by strengthening government capacity to involve the private sector in public assets. They engage the innovation and incentives of the private sector to deliver public infrastructure projects. The Canadian federal government encourages the use of PPPs through PPP Canada, which incorporates, among other measures, a CAN 1.2 billion fund offering co-financing for PPP projects undertaken by provinces, territories and local governments. PPP Canada does not procure investments, but rather helps build capacities for PPPs at different levels of government through detailed guidance and incentives to develop high quality projects.

\section{Screening and Advisory Services}

In addition to the advice and support provided, PPP Canada has developed specialized advisory services oriented toward federal departments and agencies, as well as other levels of government. As the Government of Canada's center of expertise, PPP Canada is dedicated to building a base of specialized knowledge and best practices, and sharing this expertise with governments seeking to pursue this innovative approach.

\section{Examples of P3s projects}

Large-scale PPP infrastructure projects are complex, long-term investments. Though PPPs can deliver better value to taxpayers, this is only possible when they are correctly developed and effectively executed. It can provide many benefits when applied to the right projects. For example, PPP Canada has facilitated projects in water infrastructure (e.g. Saint John Safe Clean Drinking Water, Saint John NB), local road infrastructure (e.g. North Saskatchewan Bridge, Edmonton AB; Chief Peguis Trail Extension, Winnipeg MB), public transit infrastructure (e.g. Lincoln Station Project, Coquitlam BC; Barrie Transit Facility Project, Barrie ON), core national highway system infrastructure (e.g. Regina Bypass Project, Regina Saskatchewan), regional and local airport infrastructure (e.g. Iqaluit International Airport Improvement Project, Iqaluit NU), solid waste management infrastructure (e.g. Organic Biofuels Facility Project, Surrey BC) and green energy infrastructure (e.g. Kokish River Hydroelectric Project).

Source: OECD (2013), Investing Together: Working Effectively Across Levels of Government, OECD Publishing; and McBride, J. (2013) "Broadening and Deepening the Canadian P3 Market: A Case Study of PPP Canada and the P3 Canada Fund" presentation at the OECD 6th Annual Meeting of Senior PPP Officials, April 15 - 16, 2013, Paris, France, http://www.p3canada.ca/.

\section{Responding to the challenges: Measures to stimulate subnational investment}

Since 2010, several countries have adopted measures to stimulate subnational investment. For instance in Australia, the Minister for Regional Australia, Regional Development and Local Government announced in February 2013 an increase of AUD \$1.28 million in grants to councils in order to fund infrastructure. In Canada, the Building Canada Plan aims at implementing CAD \$53 billion of investments over 10 years starting 2014-2015 including over CAD \$47 billion in new funding to support local and economic infrastructure projects. Besides supporting subnational governments for future investments, CAD 6 billion will be granted to provinces, territories and municipalities under current infrastructure projects. In Denmark, municipalities have agreed with the central government to limit their operating expenditure but to increase investment. In Estonia, an important stimulus plan based on public investment was launched, financed through Kyoto emission permit sales and EU structural funds.

In Germany, an Expert Commission recommended mechanisms for ensuring sustainable public investment and for strengthening local infrastructure to deal with insufficient maintenance of public infrastructure. In order to sustain public investment, the Commission recommended the creation of specialised institutions that can support regional and local authorities in connection with new investment and maintenance in specific categories of infrastructure. To strengthen local infrastructure, the creation of a "National Investment Pact for Municipalities" was proposed in order to increase municipal investment, as well as reinforce the municipal capacities so that projects could be economically and efficiently planned and implemented. The progressive development of "public collaborations", which are procurement models where collaboration between municipalities is a key element, has also been proposed to strengthen subnational infrastructure investment (Expert commission's report on "Increasing investment in Germany", 2015). 


\section{The European Investment Plan}

Announced in November 2014, the Juncker Plan's objective is to generate at least EUR 315 billion (2\% of 2015 EU GDP) of additional investment over three years, mainly from private sources, with a focus on infrastructure, innovation and finance for SMEs (Box 4). The purpose is to boost EU growth - expected to be $2 \%$ GDP in 2016 and $2.1 \%$ in 2017 - as investments are forecasted to be below their 2007-level in 2017 (European Commission, 2016). The European Investment Plan also encourages investment initiatives with financial contributions from subnational governments: SNGs can apply for funding if projects are above a certain threshold; investment projects may be enhanced through "investment platforms" which are defined as special purpose vehicles, managed accounts, contract-based co-financing or risk-sharing arrangements. However, the 2016 survey of EU subnational governments by the CoR indicated an important information gap for the implementation of the European Investment Plan: only $7 \%$ of respondents were well informed about how the European Fund for Strategic Investments (EFSI) could be used in their region/city (Box 4).

\section{Box 4. The European Investment Plan and EU subnational governments}

To meet its objective, the European Investment Plan consists of three strands: i) mobilising investment finance without creating public debt; ii) supporting projects and investments in key areas (infrastructure, education, research and innovation); and iii) removing sector specific and other financial barriers to investment. The Plan calls for determined efforts to remove regulatory bottlenecks, integrate infrastructure networks and implement and develop the existing rules at national, regional and European levels.

To implement the European Investment Plan, the European Fund for Strategic Investments (EFSI) was established within the European Investment Bank (EIB) and endowed with a risk absorbing capacity of EUR 21 billion, including EUR 5 billion from EIB resources and an EU guarantee of EUR 16 billion. Under certain conditions, national authorities will be able to combine European Structural and Investment Funds with EFSI support to enhance risk-bearing capacity and thus the ability to attract private sector financing (EU Commission, 2016). The medium-term success of the Plan will hinge on its ability to leverage private investment, for which EIB lending will be critical in this respect. The EUR 315 billion investment target presupposes a multiplier of 15: the EFSI guarantee should enable 3 times as much EIB funding, which will be used to finance an average $20 \%$ of investment projects (the remainder coming from the private sector). This requires selecting projects which are attractive for private co-funding and (to avoid crowding-out) which would not otherwise be carried out.

The European Investment Plan also encourages investment initiatives with financial contributions from subnational governments: SNGs can apply to funding, if projects are above a certain threshold; investment projects may be enhanced through "investment platforms" which are defined as special purpose vehicles, managed accounts, contract-based co-financing or risk-sharing arrangements (Article 2.4. EFSI regulation). These platforms provide several advantages for subnational governments. They allow to aggregate small-size projects, reduce transaction and information costs and provide more efficient allocation of risks between investors. Some existing "investment platforms" will be reinforced by the EFSI, such as the European Energy Efficiency Fund (EEEF) in the energy sector or the Marguerite Fund, but only few of them have been implemented so far.

The 2016 survey of EU subnational governments by the CoR showed an important information gap for the implementation of the European Investment Plan. The results show that only $7 \%$ of respondents were well informed about how the EFSI could be used in their region/city, even though a significant group of $53 \%$ had heard about it and had some knowledge ( $35 \%$ had basic information and $18 \%$ were somewhat informed). The regions were far generally better informed (19\% of them were "well informed" about the possibility of using the EFSI in their regions), followed by medium-sized municipalities ( $8 \%$ of them). Only $8 \%$ of respondents confirmed that the public administration in their city/region cooperated with national or regional promotional banks to ensure that SMEs could receive financial support under the EFSI, or was likely to do so in 2016-2017.

The Survey also found that, despite their awareness of the Investment Plan for Europe, subnational governments faced capacity constraints (e.g. a lack of technical expertise) within the public administration at local level (31\% of respondents) and encountered difficulties in finding other investment partners (28\%). A burdensome administrative procedure (24\%) was another reason why subnational governments did not use the investment platform mechanisms under the EFSI.

Sources: Committee of the Regions (2016), Results of the CoR online consultation on obstacles to investments at local and regional level, http://cor.europa.eu/en/events/Documents/ECON/results-survey-obstacles.pdf; European Commission (2014), Commission communication on the investment plan for Europe, COM 2014903 Final, available at: http://data.consilium.europa.eu/doc/document/ST-16115-2014-INIT/en/pdf. 


\section{Addressing governance challenges specific to SNGs: Implications and recommendations}

Increasing SNG investment efficiency is crucial to compensating for the large investment gap in recent years. The public governance dimension is just as important as the financing aspect in contributing to efficient public investment and growth outcomes at both the national and subnational levels (Box 5). By scaling up good practices in selecting and delivering new infrastructure projects, SNGs could deliver significant improvement in infrastructure productivity.

\section{Box 5. The governance of public investment and economic performance: Insights from the literature}

A great deal of work has taken place in recent years on assessing the relationship between institutional quality and economic performance. It is now widely accepted that there is a link between the two (Woolcock, 1998; North, 1990; Rodrik et al., 2004; Acemoglu et al., 2005), though the causal link between them remains controversial (OECD, 2013). A growing body of literature underscores the role that the legal, institutional, and procedural arrangements for public investment management play in determining the level, composition, and impact of public investment. Improvements in public investment management practices are estimated to reduce the efficiency gap above by two-thirds on average across countries (IMF, 2015).

Recent OECD analyses have assessed the impact of institutional quality on economic performance (in terms of GDP growth) and the returns to public investment (Rodriguez-Pose and Garcilazo, forthcoming; D'Costa et al., forthcoming), and focused more recently at the regional level. Filipeti and Reggi (2012) find a positive correlation between the quality of government and the growth impact of EU spending in European regions. Becker et al. (2011) show that human capital and quality of government endowment have a clear impact on turning EU transfers into economic growth. The quality of government may be a key factor of whether greater cohesion investment is translated into greater growth (OECD, 2013). The European Union (EU) has also adopted the view that poor institutions undermine the returns of public investments. As stated in the EU"s Fifth Cohesion Report, "poor institutions can, in particular, hinder the effectiveness of regional development strategies" (EU, 2010). The quality of local institutions is thus considered to mediate the potential returns of investment in regional cohesion: the weaker the institutional setting, the greater the problems in transforming European regional development investment into growth and development. Regions with weak institutions have been considered as incapable of absorbing regional development and cohesion funds and to make the most of the investments taking place in their territory (OECD, 2013).

More particularly, at the planning stage, OECD (2014) underscores the importance of effective, integrated strategic planning at the national and subnational level, while Schwartz and others (2008) emphasizes the importance of institutional arrangements to minimize the risks associated with PPPs. Finally, at the implementation stage, Dabla-Norris and others (2012) underscore the role of firm expenditure controls, regular project execution reporting and strong project management arrangements in order to deliver investment projects on time and on budget (IMF, 2015).

Sources: OECD (2013), Investing Together: Working Effectively across Levels of Government, OECD Publishing, Paris, http://dx.doi.org/10.1787/9789264197022-en. IMF (2015), "Making Public Investment More Efficient", IMF Policy Papers Series, Washington D.C., http://www.imf.org/en/Publications/Policy-Papers/Issues/2016/12/31/Making-Public-InvestmentMore-Efficient-PP4959; Rodriguez-Pose, A. and E. Garcilazo (2013), "Quality of Government and the Returns of Investment: Examining the Impact of Cohesion Expenditure in European Regions", OECD Regional Development Working Papers, No. 2013/12, OECD Publishing, Paris, http://dx.doi.org/10.1787/5k43n1zv02g0-en.

Clearly, some governance challenges are more specific to subnational governments, which by their nature are inherently fragmented and diverse in their management capacities and resources. Coordination across levels of government for effective infrastructure investment is necessary but difficult in practice. Many SNGs, in particular small municipalities, as well as inter-municipal cooperation bodies, lack the expertise to design and run infrastructure investment. In 2014, the OECD adopted a 'Recommendation of the Council on Effective Public Investment across Levels of Government', which focuses on multilevel governance challenges and ways to overcome them. ${ }^{6}$ The results of the OECD-CoR survey provide a comprehensive picture of the governance challenges reported by SNGs (Figure 12) as well as best practices adopted by SNGs. 
Figure 12. Main challenges perceived by SNGs with respect to strategic planning and implementation of infrastructure investment

\section{Major challenge Somewhat a challenge}

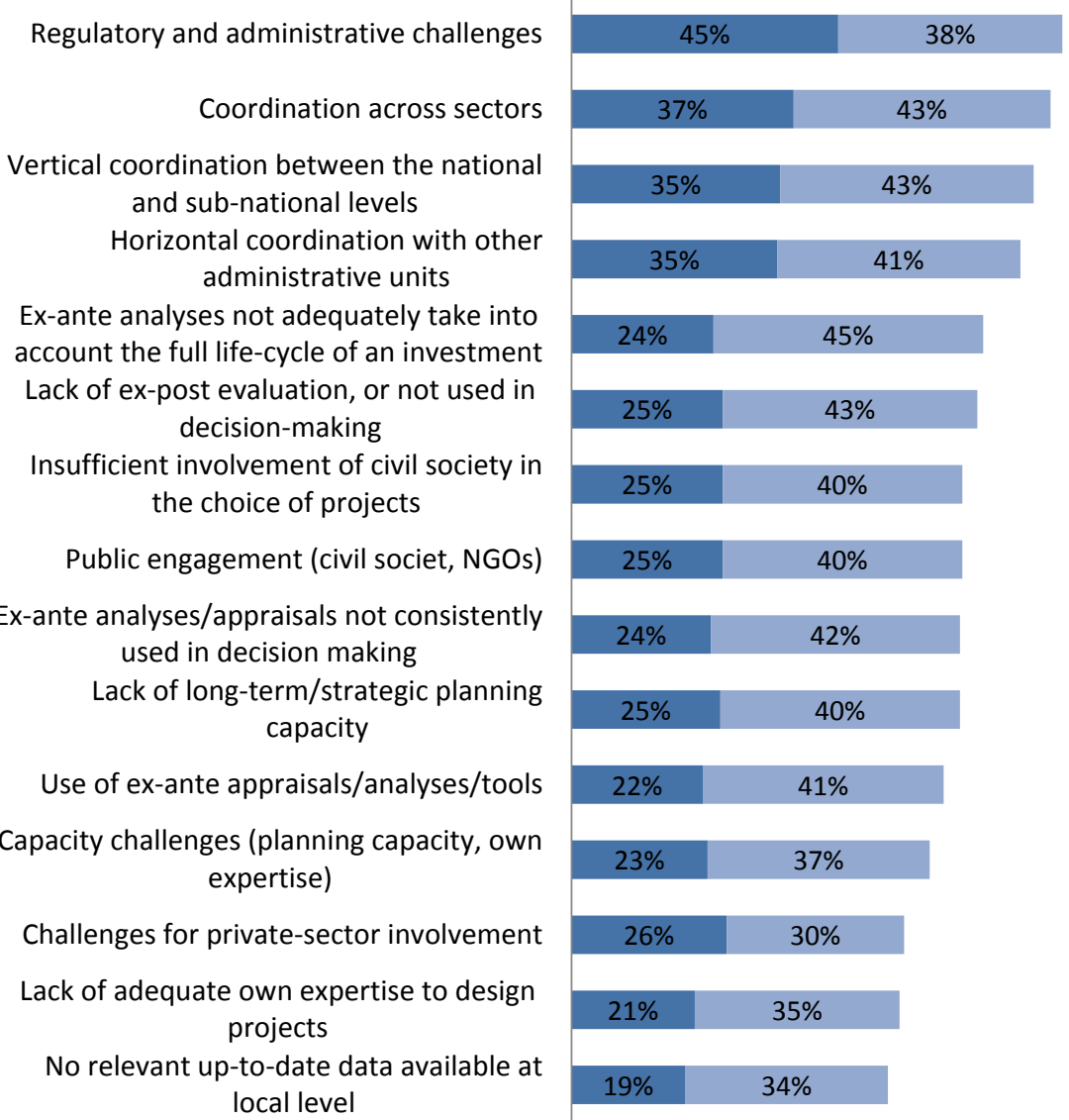

Source: Results of the OECD-CoR survey of subnational governments in the European Union (2015).

While the challenges are numerous, the results of the survey show that many SNGs are implementing a variety of strategies to improve the management of infrastructure investments (Figure 13). Improving medium-term planning, benefiting from external support to design projects, and improving cooperation with neighbouring SNGs were reported as the most important practices by all categories of SNGs. When looking in more detail, slight variations across SNGs may be observed. Small municipalities see external support for designing projects and simplification of public procurement as the most important practices, while $70 \%$ of large municipalities, those with more than 50,000 inhabitants, have a greater interest in increased stakeholder engagement. Regions emphasised increased external support for designing projects and more rigorous criteria to select investment projects. 
Figure 13. Practices that helped the management of infrastructure investment in SNGs

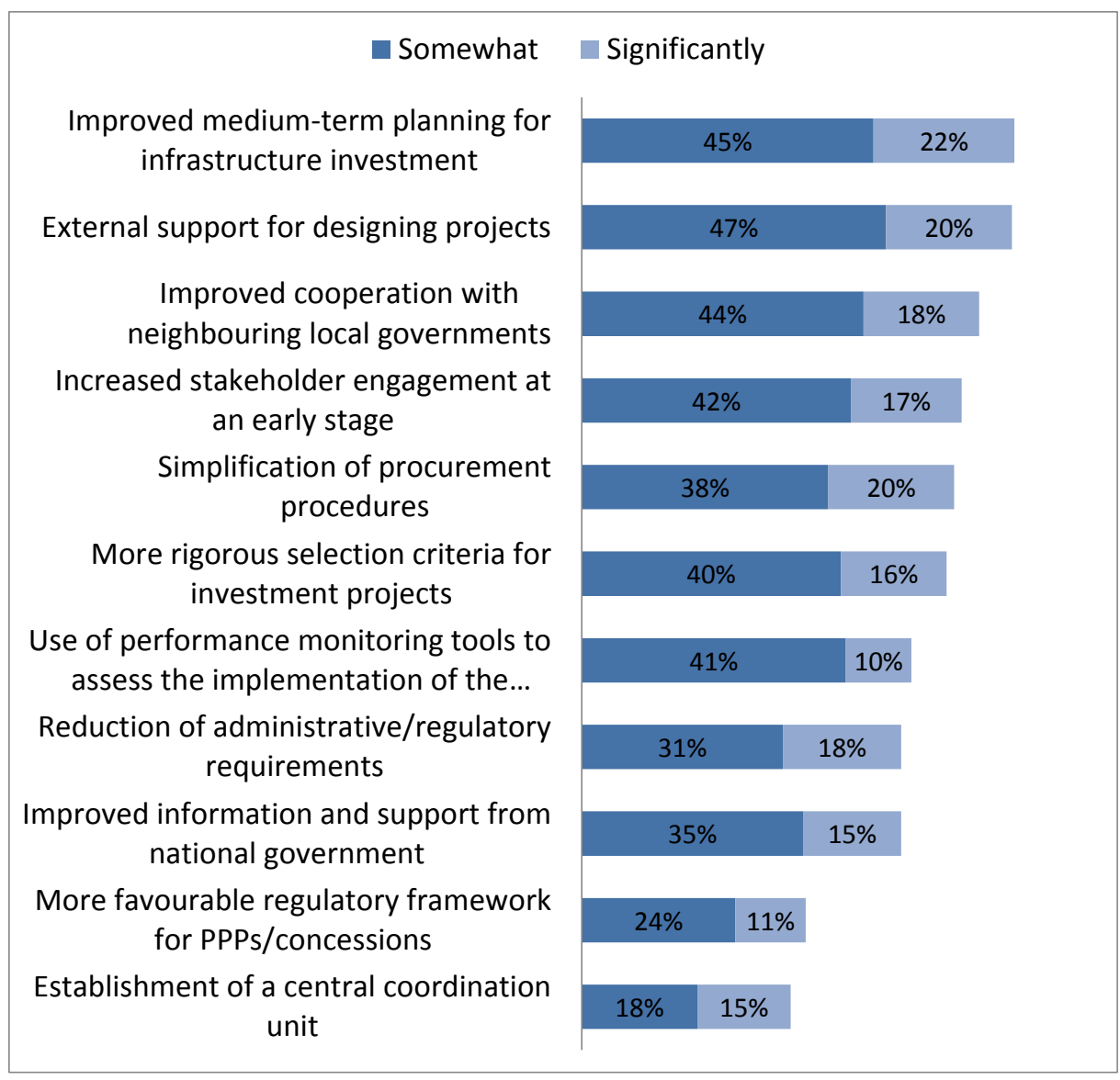

Source: Results of the OECD-CoR survey of subnational governments in the European Union (2015).

Below we explore the issues flagged by SNGs as top challenges and explore possible solutions, including: i) using a long-term perspective to better design and plan infrastructure investment; ii) better coordinating across levels of government, jurisdictions, and infrastructure sectors; iii) improving performance monitoring and evaluation; and iv) improving framework conditions, notably regulatory and procurement frameworks.

\section{Designing and planning infrastructure using a long-term perspective}

The lack of capacity to adequately design and plan infrastructure investment using a long-term perspective was seen as a key challenge by the majority of survey respondents. Two-thirds of SNGs reported that the capacity to design long-term infrastructure strategies was lacking in their locality. In addition, 56\% of SNGs reported insufficient in-house expertise to design infrastructure projects. This was particularly the case with small municipalities and with inter-municipal structures. A lack of expertise hinders the ability to turn local strategies into viable investment projects. Furthermore, although ex ante appraisals, analyses, and tools such as cost-benefit analysis, environmental impact assessment, and territorial impact assessment had been implemented, two-thirds of SNGs lamented that results were not consistently used in decision-making. A similar proportion of SNGs reported failure to take into account the full life cycle of infrastructure investment when designing projects, a lapse that most often leads to fiasco. Finally, two-thirds of respondents also reported insufficient or inadequate involvement of civil society representatives, citizens, and non-governmental organisations in the choice of infrastructure projects as a challenge, with one-quarter of respondents considering this a major challenge that can lead to acceptance and support problems. 
Improvements in multi-year planning for infrastructure investment were considered by all categories of SNGs as the most important practices for improving the governance of investment. Indepth multi-year planning of subnational investments is essential to improve investment efficiency. This approach has been used extensively in New Zealand, where all SNGs are required to adopt plans that lay out spending and investment intentions for the coming ten years. The plans are designed to ensure that investment decisions by SNGs are integrated and linked to each community's desired outcomes. France now recommends that SNGs use multi-annual investment plans more systematically.

A comprehensive, multi-year view of costs, benefits, and risks is also important, but the survey results show the challenges in obtaining such a perspective. Increasingly, this means evaluating value for money and the combination of quality, features, and price over the life cycle of an investment (OECD, 2008). Comprehensiveness also means a broad view of benefits and costs, including 'accounting for the benefits if new infrastructure generates cross-jurisdictional spillovers (Sutherland et al, 2009). It is also essential to construct a detailed analysis of long-term costs entailed by each option. Toward this end, the London Infrastructure Plan 2050, for instance, aims to improve infrastructure planning and delivery through systemic assessment of needs and consideration of different types of infrastructure, as well as their total cost and possible methods of funding and financing.

While growth objectives are crucial, an exclusive focus on growth may overlook important social or environmental costs or benefits of an investment. Governments should assess different types of risks and uncertainty associated with public investment, including those pertinent to a particular region or locality, as part of an appraisal. In the state of Victoria, Australia, for example, strong ex ante monitoring mechanisms are in place, especially through an innovative High Value High Risk (HVHR) process that is used for investments with values above a defined threshold or for those that entail high risk. Under the HVHR process introduced in 2010, such investment projects undergo rigorous scrutiny and approval processes, with increased oversight over various stages of investment development, procurement, and delivery. The process also includes the development of performance indicators that serve as the basis for monitoring infrastructure performance after implementation (OECD, 2015d).

Involving private and public actors in planning at different stages of public investment can have substantial benefits, such as reduced costs, better decisions, and greater support for projects. The involvement of civil society and businesses may also lead to precious information gains. For instance, the London Infrastructure Plan 2050 was elaborated in an inclusive way with involvement and feedback from businesses, government, and infrastructure providers. In Germany, the decision to build a new runway at Frankfurt Airport was accompanied by a mediation process initiated by the state government of Hesse with the goal of reconciling concerns about noise and other environmental impacts with the economic case for the new runway. The process was initiated prior to the decision to build the runway and included extensive consultations with project proponents and opponents. Most recommendations made by the mediators were implemented in the planning process, and after the end of the mediation process, a regional forum contributed to the dialogue among stakeholders until the planning process was completed and construction had started (OECD, 2015d).

\section{Coordinating across levels of government, jurisdictions, and infrastructure sectors}

Another set of key challenges reported by more than three-quarters of SNGs relates to coordination across levels of government, jurisdictions, and infrastructure sectors.

\section{Vertical coordination among levels of governments}

Among 15 dimensions of institutional quality for efficient public investment management, central-local coordination is the one where advanced economies tend to fare the worst (IMF, 2015). 
Findings from the OECD-CoR survey confirm that challenges in vertical coordination between SNGs and national governments are prominent. The most common vertical coordination challenge, mentioned by $84 \%$ of SNGs, is a mismatch between local or regional needs and those given priority at the national level. This is particularly marked for large SNGs: regions, counties, and metropolitan areas with more than 500,000 inhabitants. Furthermore, the lack of a long-term infrastructure strategy at the national level was reported by $78 \%$ of respondents as a challenge, and by $37 \%$ as a major one. It is particularly problematic for regions and small municipalities. Added to these challenges is a lack of political will or administrative culture needed to work across different levels of government, particularly noticeable for inter-municipal structures, possibly because this type of structure tends to be weaker from a political perspective, especially when not elected, thus reducing the will to cooperate.

Coordination between levels of governments is needed in order to reduce asymmetries of information regarding investments, help reduce funding gaps, and ensure alignment of strategic priorities for infrastructure development. Platforms for vertical coordination have been established in several OECD member states, in particular federal countries. In Australia, for instance, the independent statutory authority Infrastructure Australia works with states, territories, local governments, and the private sector on the basis of rigorous cost-benefit analysis to identify investment priorities and the policy and regulatory reforms necessary to enable timely and coordinated delivery of national infrastructure investment. It also advises Australian subnational governments on how to manage infrastructure gaps and bottlenecks that hinder economic growth. In Canada, the federal government is represented in the provinces via structures such as regional federal councils and regional development agencies, whose interests lie not only in representing the federal government's priorities in the provinces but also in conveying provincial preferences to the federal authorities. The result is tripartite agreements (i.e. formal contractual arrangements among federal, provincial, and local authorities) that support the implementation of infrastructure policies. In France, territorial strategies are formalised as contractual arrangements across levels of government through state-region planning contracts (contrat de plan État-région) that stipulate co-decision and cofinancing of interventions.

\section{Horizontal cooperation for economies of scale}

Although the potential benefits of coordination across jurisdictions may seem obvious, coordination was perceived as a significant challenge by most SNGs surveyed. More than threequarters of SNGs reported the absence of a joint investment strategy with neighbouring cities or regions. Nearly the same percentage of SNGs also considered the lack of incentives - including financial - to cooperate across jurisdictions to be a problem.

Horizontal cooperation between SNGs is critical for reaching economies of scale, in particular through the pooling of some infrastructure investments. Moreover, horizontal coordination allows SNGs to share information about their current and forthcoming investments and may help limit problems linked to duplication of investments. Such coordination may take place in dialogue platforms, through the consolidation of several SNG plans, or through financial incentives from the national government. For instance, Switzerland relies on three major mechanisms to promote cooperation across regions: cantonal conferences, inter-cantonal agreements, and cross-border cooperation. The federal government provides up to CHF 500000 annually over three to six years for innovative multi-jurisdiction projects (OECD, 2015d). In countries with a high level of municipal fragmentation, municipal mergers - rather than just coordination - might be recommended as a way to enhance the scale of subnational investment and make economies of scale.

Horizontal cooperation may also imply the mutualisation of capital funding toward facilitating access to finance. In several countries, local government funding agencies have been created to pool the borrowing needs of local authorities and to issue bonds in capital markets. The Scandinavian countries and the Netherlands have had funding agencies for a long time, and the trend is quickly 
spreading across other parts of Europe. In France, a Local Government Funding Agency (Agence France Locale) was created in December 2013 to raise cost-efficient resources in capital markets by pooling together the funding needs of its members. New Zealand established a Local Government Funding Agency as a debt vehicle that raises bonds on the local and international markets. Similar discussion is underway in Australia, as well. Such agencies may also contribute to strengthening local capacities. For example, the Swedish Kommuninvest also operates as a knowledge hub, providing research, advice, and training for local authorities.

\section{Coordinating investments across several sectors}

Subnational governments face various types of difficulties linked to different forms of coordination, e.g. between levels of government, jurisdictions, or infrastructure sectors. One-third of SNGs consider the lack of coordination between sectors (e.g. transport, housing, broadband, water, and spatial planning), as a major challenge. For another $45 \%$ it is 'somewhat a challenge'. This is particularly the case for large SNGs. For example, in Hamburg (Germany), roads that had just been rebuilt to make special bus lanes had to be torn up again in order to dig sewage canals. When infrastructure investments are planned taking into account other sectors, complementarities that may save time and financial resources can be exploited. "Value +" is another example which illustrates the benefits of coordinating investments across sectors. It is a three-year project, carried out across four European countries (Belgium, Germany the Netherlands, and the United Kingdom), which involves seven green infrastructure investment projects (e.g. parks, green space, buffer zone, information and learning opportunities along an industrial heritage cycle route, etc.). This infrastructure project demonstrates that cross sector strategies tend to increase sustainable stakeholder engagement and local authority involvement in planning, delivering and maintaining investments (i.e. in establishing clear objectives, standardising measures of performance to allow quantifiable comparisons, securing funding streams for the duration of the project and beyond, etc.).

Cross-sectoral infrastructure investment is challenging but, when implemented correctly, may be a major source of economies of scale and can avoid duplication of costs. Many OECD countries seek to enhance coordination across sectors for investments through the use of broad strategic investment plans, financial incentives, or specific contracts for cross-sectoral investments. In Austria, for instance, integrated territorial strategies for public investment are key instruments to encourage crosssectoral coordination and multi-year planning ${ }^{7}$.

\section{Performance monitoring and evaluation}

Monitoring and evaluation are crucial but often neglected elements of any strategic or project process. Unfortunately, even when monitoring systems exist, they are frequently pursued as administrative exercises, as opposed to tools for planning and decision-making, as reported by $66 \%$ of SNGs surveyed. In the case of ex post impact evaluations of infrastructure projects, the challenge seems even greater. A majority of respondents-71\%-reported the lack of ex post impact evaluations as a challenge, and for 32\% it was reported as a major problem. However, only $19 \%$ of small municipalities cited the lack of ex post evaluations as a challenge, possibly due to the fact that evaluation of large projects is more complex.

Previous OECD work has also identified the lack of ex post evaluation as a challenge at the national level (OECD, 2011). For example, in the United States, the absence of ex post evaluation was identified as a major challenge for the implementation of the investment recovery programme in 2008-9 (ARRA). The only requirement for performance monitoring was based on inputs, such as kilometres of roadway or level of expenditures, rather than outcomes or long-term objectives (GAO, 2010). Ex post evaluations are clearly lacking in the majority of OECD countries. In the United Kingdom, the Parliament's Public Accounts Committee and the National Audit Office recently criticised the Department for Transport for its lack of ex post evaluation, especially for rail projects (UK Department for Transport, 2015). 
Careful monitoring of infrastructure investment not only helps track progress but also contributes to decision-making regarding the direction of current and future projects. However, as the OECDCoR survey shows, many SNGs face difficulties in conducting proper monitoring and consider it to be an administrative burden. In order to harness the productive value of the information gained through monitoring and evaluation, governments should produce information that is timely, relevant, and actionable and should use it in a meaningful way (OECD, 2014).

In Spain, the region of Galicia participated in a European Commission pilot project based on using output and outcome indicators as a central mechanism for managing public investment funded by the EU. Certain principles of performance budgeting were implemented by the regional government in order to use the outputs and outcomes as input for 2013 budget negotiations. The ultimate goal was to reorient the management of public investment toward results as opposed to expenditures (Hulbert, 2012). In Italy, the Basilicata region has a Public Investment Evaluation Unit within the Department for Structural Funds that is responsible for monitoring and evaluating all public investments in the region, checking the consistency of strategic projects with respect to the regional development and annual financial plans, and performing impact evaluations of public investment projects on employment and production.

As noted above, ex post evaluations are crucial for assessing the outcomes of infrastructure investment, but such evaluations remain a challenge for SNGs. Where physical infrastructure is concerned, the primary task is to identify real economic impact.

\section{Regulatory and procurement frameworks}

The large majority of SNGs respondents-90\%-considered excessive administrative procedures and red tape to be a challenge, and for more than half of the respondents, a major one. The existence of lengthy procurement procedures and the delays caused by such systems also ranked high among the hurdles faced by SNGs in implementing infrastructure projects. Furthermore, the existence of multiple contact points for completing these administrative procedures was seen as a problem by three-quarters of SNGs.

Even when procurement rules are set at the national level, SNGs have a role in facilitating their implementation. Collaborative procurement across levels of government, e.g. purchasing alliances, networks, framework agreements, and central purchasing bodies, can also help improve procurement capacity. For example, in France, many SNGs are seeking to reach economies of scale by creating agencies that regroup their purchases (Cour des Comptes, October 2015). In 2014, several regionsincluding Aquitaine, Centre-Val de Loire, Lorraine, Île-de-France, Pays de la Loire, and RhôneAlpes - created an association to pool their purchases related to information systems. The central purchasing body can support the local level with market analysis, procurement strategy, and negotiation of framework contracts with economic operators. This ensures coverage of, for example, the costs of storage and logistics involved in purchasing goods, an often overlooked problem at the subnational level. SNGs can also seek to develop electronic procurement. For instance, Galicia, in Spain, has developed a web platform for public procurement procedures for all public entities, including municipalities.

In most unitary countries, regulatory frameworks are established at the national level, whereas in federal countries they may be imposed at the sub-federal state or provincial level. However, even when frameworks are designed at the national level, SNGs should be involved in setting up these conditions, for example through regular consultation of new norms that may impact SNGs. Regulatory coherence is of particular importance in infrastructure sectors such as energy, ICT, and water, owing to the greater degree of regulation to which such activities are typically subjected (OECD, 2015e). Even relatively basic public works projects may be impeded by a lack of regulatory clarity or coherence. In Australia, through the Council of Australian Governments (COAG), governments agreed to revise their regulatory impact assessment procedures to consider whether an 
existing regulatory model outside their jurisdiction would efficiently address a policy issue in question and whether a nationally uniform, harmonised, or jurisdiction-specific model would be best for the community.

\section{Improved subnational governance of infrastructure is connected to better outcomes}

The results of the OECD-CoR survey facilitated the elaboration of an indicator to measure the degree of governance challenges faced by SNGs (hereafter, indicator of subnational investment governance). It is based on 20 variables related to the governance challenges survey respondents reported, from the design of strategic planning to the implementation and monitoring of infrastructure investment projects. Final scores summing the responses of each respondent are based on a total of 100 points: a high final score is associated with a lower degree of perceived challenges and a more effective governance of infrastructure investment (see Annex 4).

Final scores summing the responses of respondents range from 6 to 86.5 out of 100 . The average score of the 255 SNGs surveyed is 39.3. For the entire European Union, 16\% of SNGs surveyed have a very high score, $30 \%$ a high score (above the average of 39.3); while $38 \%$ have a score below average and $16 \%$ a very low score. The variations are also important within the different categories of SNGs. Interestingly, no single category of SNGs emerges as having better governance indicators than others. Variations are also very important across SNGs within countries. For example, in Germany $27 \%$ of SNGs have a very high score, $41 \%$ a high score, $24 \%$ a medium score and $8 \%$ a low score (Figure 14). In Estonia, 29\% have a very high score, 33\% a high score and a medium score, and $4 \%$ a low score.

Figure 14. Variations of subnational investment governance scores across SNGs: the example of Germany

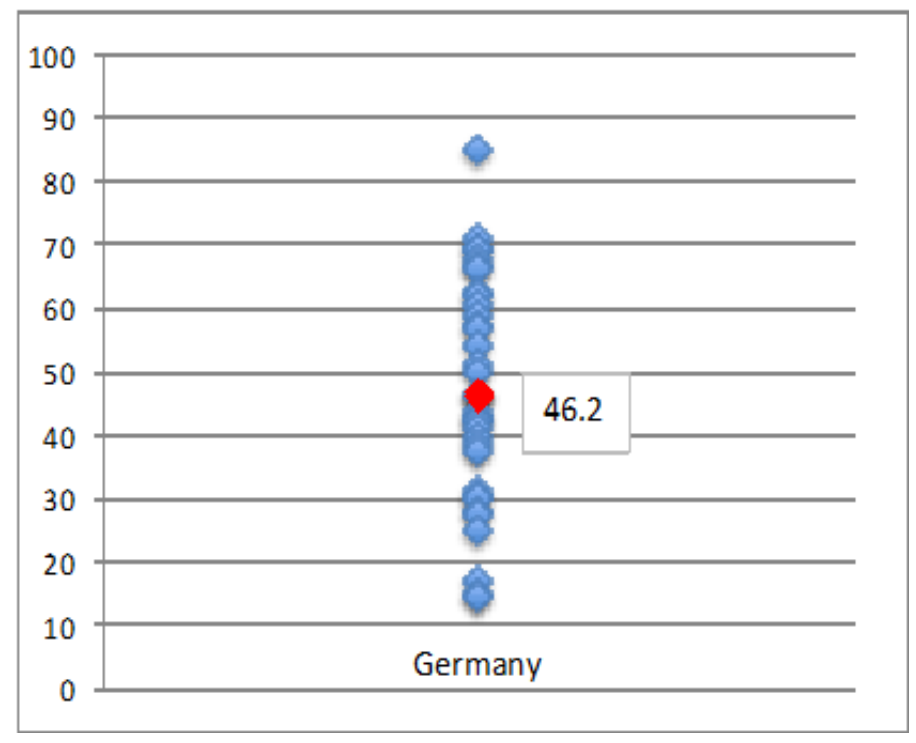

Source: Results of the OECD-CoR survey of subnational governments in the European Union (2015).

It would be interesting to study the correlation of this subnational investment governance indicator with socio-economic indicators at the TL2 (regional) level. Unfortunately, the small number of respondents to the OECD-CoR survey among regional governments (47) is a strong constraint. Nevertheless, the governance indicator based on answers to the OECD-CoR survey is positively correlated with indicators of citizen perception of the quality of governance developed by the University of Gothenburg ${ }^{8}$ (Figure 15). There is also a statistical correlation between our subnational investment governance indicator and the average regional growth rate over the period 2001-2011. This statistical correlation (Pearson r: 28.4\%) must be confirmed by further research. 


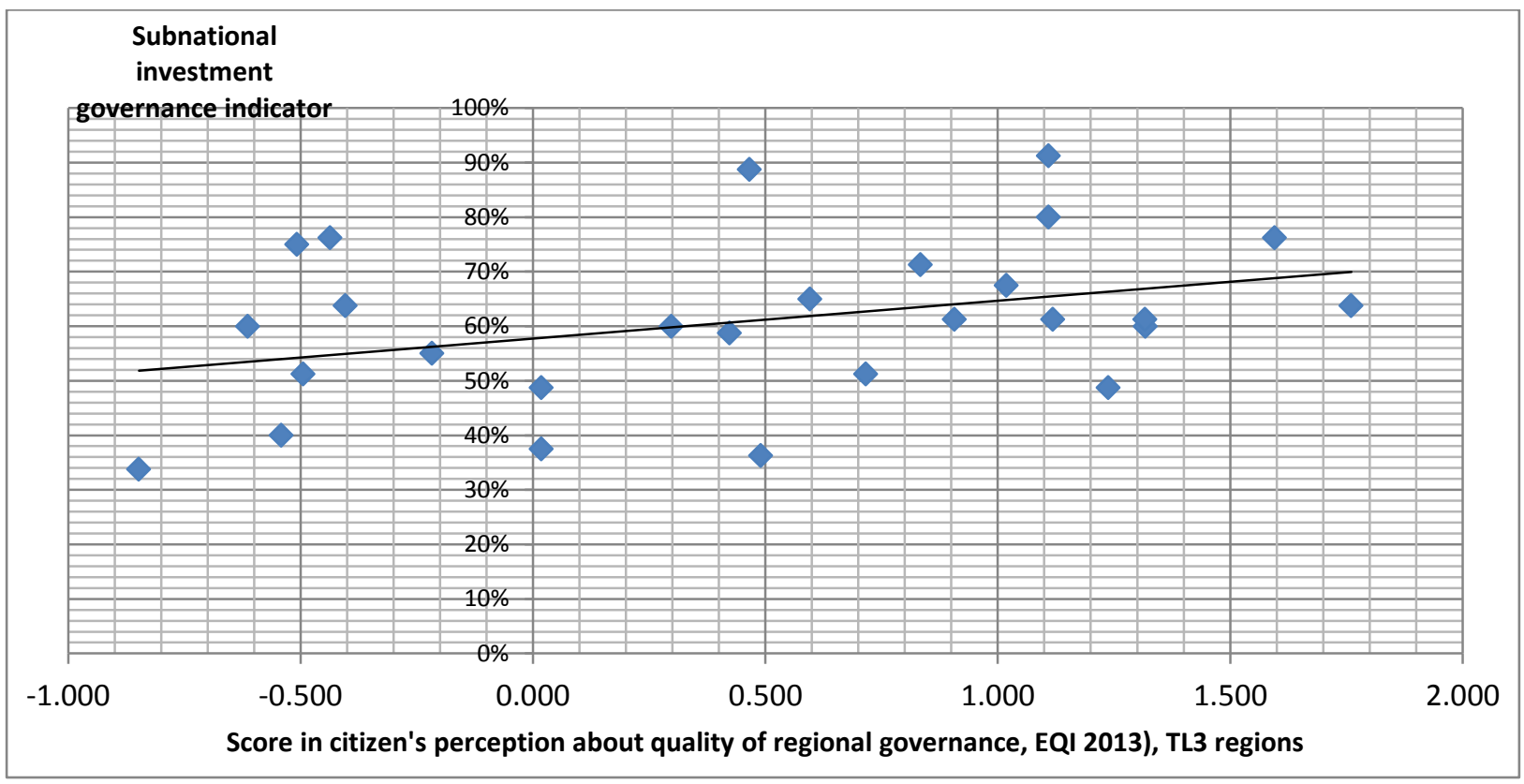

Note: $\mathrm{n}=27$, Correlation coefficient: $41.3 \%$ statistically significant at the $95 \%$ confidence level.

Source: OECD-CoR survey, European quality of governance index, available at: https://nicholascharron.wordpress.com/europeanquality-of-government-index-eqi.

\section{Conclusion and recommendations}

This paper aimed at showing that many of the governance and financing challenges for infrastructure investment have specific implications for subnational governments, hence the need to focus more systematically on this angle of analysis. To meet the many challenges reported by SNGs, various innovative practices are being put in place to improve the results of infrastructure investment at the subnational level. Such practices need to be shared more broadly to promote learning across SNGs, both within countries and at the international level. The OECD has developed an implementation toolkit for the Recommendation on Effective Public Investment across Levels of Government which provides more detailed guidance to policy-makers, with a set of indicators and good practices.

Subnational and national solutions should complement each other to foster effective subnational infrastructure investment. For SNGs, some priorities are to:

- Focus on improving medium-term planning as a top priority and better connect planning and budgeting frameworks to have a multi-year approach to investment.

- Foster integrated cross-sectoral investment strategies at the local level to benefit from complementarities across sectors.

- Seek to mutualise resources, both financial and human, to invest at the relevant scale and thereby achieve economies of scale. Further, SNGs should seek to mutualise procurement and develop electronic-procurement, in particular in small municipalities and at the metropolitan level. 
- Assess operations and maintenance costs of infrastructure investment and plan for future financing. Consider the full life cycle of infrastructure investment when designing the project.

- Better connect monitoring and evaluation to budgeting and policy-making.

National governments should focus on the following aspects to promote sound subnational investment:

- Encourage the development of medium-term expenditure frameworks at the subnational level and foster greater connection between planning and budgeting.

- Strengthen multi-level governance arrangements to ensure alignment of investment strategies and priorities across national and subnational governments.

- Provide formal incentives to foster cross-jurisdictional cooperation.

- Focus on subnational capacity building for infrastructure investment, especially the use of complex financial tools, through a differentiated approach targeting different needs in different types of regions and localities.

\section{REFERENCES}

Albalate, D., Bel, G., and Fageda, X. (2015), "When supply travels far beyond demand: Causes of oversupply in Spain's transport infrastructure", Transport Policy, Elsevier, vol. 41(C), pages 8089., available at: http://www.sciencedirect.com/science/article/pii/S0967070X15000414.

Alesina, A. and S. Ardagna (1998), "Fiscal Adjustments - Why they can be Expansionary?", Economic Policy, Vol. 13(27).

Alesina, A. and R. Perotti (1995), "Fiscal Expansions and Adjustments in OECD Countries", Economic Policy, Vol. 21.

Alesina, A. and R. Perotti (1997), "Fiscal Adjustments in OECD Countries: Composition and Macroeconomic Effects", IMF Staff Papers, Vol. 44(2).

Allain-Dupré, D., C. Hulbert and C.Vammalle (2013): "Public Investment at Central and Subnational Levels: An Adjustment Variable for OECD Countries in the Present Context of Austerity?", paper prepared for the OECD workshop on Effective Public Investment at Subnational Level in Times of Fiscal Constraints: Meeting the Co-ordination and Capacity Challenges.

Ambrose, B.W., L. Cordell and S. Ma (2014), "The Impact of Student Loan Debt on Small Business Formation", Federal Reserve Bank of Philadelphia Working Paper, 29 March 2014, Philadelphia, http://papers.ssrn.com/sol3/papers.cfm?abstract id=2417676.

Andrews, K., and J. Swanson (1995): "Does public infrastructure affect regional performance?" Growth and Change 26: 204-216.

Berechman, J., D. Ozmen and K. Ozbay (2006): "Empirical analysis of transportation investment and economic development at state, county and municipality levels", Transportation, 33. 
Bivens, J. (2014), "The Short- and Long-Term Impacts of Infrastructure Investments on U.S. Employment and Economic Activity", Budget Taxes and Private Investment, Economic Policy Institute, Washington, www.epi.org/publication/impact-of-infrastructure-investments/.

Blöchliger, H., D. Song and D. Sutherland (2012), "Fiscal Consolidation: Part 4. Case Studies of Large Fiscal Consolidation Episodes", OECD Economics Department Working Papers, No. 935, OECD Publishing, http://dx.doi.org/10.1787/5k9fdf5xptlq-en.

Burger, P. and Hawkesworth , I. (2011), "How To Attain Value for Money: Comparing PPP and Traditional Infrastructure Public Procurement”, OECD Journal on Budgeting, Vol 2011/1

Cour des Comptes (2015), Les finances publiques locales, Rapport sur la situation financière et la gestion des collectivités territoriales et de leurs établissements publics, Octobre 2015

De la Fuente, Angel (2017), "Las finanzas autonomicas en 2016 y entre 2003 y 2016", BBVA Research Working Paper, available at (in Spanish): https://www.bbvaresearch.com/wpcontent/uploads/2017/05/Finanzas aut WP.pdf

European Commission (2007), "European Economy-Public Finances in EMU", European Commission, Brussels.

European Court of Auditors (2014), "EU-funded airport infrastructures: poor value for money", Special Report $\mathrm{N}^{\circ} 21$, available at: http://www.eca.europa.eu/Lists/ECADocuments/SR14_21/QJAB14021ENC.pdf.

Fournier, J.M. and A. Johansson (2016), "The Effect of the Size and the Mix of Public Spending on Growth and Inequality", OECD Economics Department Working Papers, No. 1344.

Jeffrey P. Cohen and Catherine J. Morrison Paul (2004): Public Infrastructure Investment, Interstate Spatial Spillovers, and Manufacturing Costs, The Review of Economics and Statistics, Vol. 86.

María Jesús Delgado \& Inmaculada Álvarez (2007): "Network infrastructure spillover in private productive sectors: evidence from Spanish high capacity roads", Applied Economics, 39:12, 1583-1597.

Expert Commission on Behalf of the Federal Minister for Economic Affairs and Energy (2015): "Increasing Investment in Germany", Expert Commission's Report on Increasing Investment in Germany.

Ezcurra, R., C. Gil, P. Pascual and M. Rapún (2005): "Public capital, regional productivity and spatial spillovers", The Annals of Regional Science, 39.

Garcia-Milà, T., T. McGuire and R. Porter (1996): "The Effect of Public Capital in State-Level Production Functions Reconsidered", The Review of Economics and Statistics, Vol. 78.

Holtz-Eakin, D. (1994): "Public-Private Capital and the Productivity Puzzle", The Review of Economics and Statistics, Vol. 76.

Holtz-Eakin, D., and A. Schwartz (1995): "Spatial Productivity Spillovers from Public Infrastructure: Evidence from State Highways", International Tax and Public Finance, 2.Moreno, R., E. López-Bazo and M. Artís (2003): "On the effectiveness of Private and Public Capital", Applied Economics, 35(6), 727-40.

IMF (2015), Making public investment more efficient, June 2015, Washington DC http://www.imf.org/external/np/pp/eng/2015/061115.pdf.

Lewis, C. et al. (2014), "Investment Gaps after the Crisis", OECD Economics Department Working Papers, No. 1168, OECD Publishing, http://dx.doi.org/10.1787/5jxvgg76vqg1-en.

McKinsey (2013), Infrastructure productivity: How to save \$1 trillion a year, McKinsey Global Institute, January 2013.

OECD (2015a), "Results of the OECD-EU consultation of subnational governments: a focus on infrastructure investment across levels of government", GOV/RDPC/TI/RD(2015)2. 
OECD (2015b), "Subnational governments in OECD countries: key data", OECD publishing, http://stats.oecd.org/Index.aspx? DataSetCode=SNGF.

OECD (2015c), "Towards a Framework for the governance of infrastructure”, OECD publishing, https://www.oecd.org/gov/budgeting/Towards-a-Framework-for-the-Governance-ofInfrastructure.pdf.

OECD (2014), "Recommendation of the Council on Effective Public Investment across Levels of Government", OECD Publishing, Paris OECD (2014b): "Regional Outlook", OECD Publishing, Paris, http://www.oecd.org/cfe/regional-policy/recommendation-effective-publicinvestment-across-levels-of-government.htm.

OECD (2013), "Investing Together: Working Effectively across levels of government", OECD Publishing, Paris, http://www.oecd.org/cfe/regional-policy/investing-together.htm.

OECD (2013), "Education at a Glance 2013: OECD Indicators", OECD Publishing, Paris, http://dx.doi.org/10.1787/eag-2013-en.

OECD (2012), "Restoring Public Finances, 2012 Update", OECD Publishing. http://dx.doi.org/10.1787/9789264179455-en.

OECD (2011), "Making the most of public investment: multi-level governance lessons from the crisis", OECD Publishing, http://dx.doi.org/10.1787/9789264114470-en.

Pereira, A., and J. Andraz (2003), "On the Impact of Public Investment on the Performance of US Industries”, Public Finance Review, 31(1), 66-90.

Shioji, E., (2001), "Public Capital and Economic Growth: A convergence Approach", Journal of Economic Growth, (6), pp. 205-227.

Sloboda, B., and V. Yao (2008): "Interstate spillovers of private capital and public spending", The Annals of Regional Science, 42.

Standards \& Poors (2014), U.S. Infrastructure Investment: A Chance To Reap More Than We Sow.

Stephan, A. (2003): "Assessing the contribution of public capital to private production: evidence from the German manufacturing sector", International Review of Applied Economics, Vol. 17.

UK Department of Transport (2015): "Ex-post evaluation at the UK Department for Transport", Presentation to CGEDD.

UK Independent Commission on Fees (2011), “Analysis of university applications for 2012/2013 admissions", The Universities and College Admissions Service, London, www.ons.gov.uk/ons/rel/household-income/middle-income-households/1977---2011-12/stymiddle-income-households.html.

World Bank (1988), “World Development Report 1988”, World Bank, Washington DC. 


\begin{abstract}
ANNEXES
Annex 1. OECD-CoR survey of subnational governments

The consultation was conducted between 31 March and 15 July 2015 in all the official EU languages. To encourage 'objective' answers, respondents were told that their answers would remain strictly confidential. The survey targeted representatives of subnational governments (regions/ provinces/ landers, counties, municipalities) in charge of investment planning/financing/ monitoring \& implementation. In total, 295 respondents participated in the survey, from all EU countries except Luxembourg. Out of these 295, 255 are subnational governments (SNGs) in the $27 \mathrm{EU}$ Member States, i.e. administrative regions, counties, and municipalities, which are the focus of the analysis in this chapter.
\end{abstract}

Although not constructed quotas, the responses for the different countries and categories of SNGs (regions, counties, large municipalities, small municipalities) are relatively balanced, with a slight over-representation of small municipalities: regions, provinces $(25 \%)$; intermediary entities (e.g. county, department) (10\%); municipalities under 50,000 inhabitants (33\%); municipalities between 50,000 and 500,000 inhabitants (22\%) as well as large municipalities with more than 500,000 inhabitants $(2 \%)$, inter-municipal cooperation structures $(8 \%)$.

More information on the survey and the methodology used to develop governance indicators is available on the OECD web site: http://www.oecd.org/effective-public-investment-toolkit/oecd-eusurvey.htm. 


\section{Annex 2. The new System of National Accounts 2008 (SNA 08)}

National accounts play a key role in macro-economic analysis and evidence based on decision making. They provide aggregates based on economic interactions between government, firms, households, non-profit institutions and the rest of the world. Initially established in 1953 by the United Nations Statistical Commission (UNSC), standards for national accounts changed in 1968, 1993 and more recently in 2008.

According to the new System of National Accounts 2008 (SNA 08), new expenditures are now included in Gross Fixed Capital Formation (i.e. investment), since they "produce assets that are themselves used repeatedly, or continuously, in processes of production for more than one year" (SNA 2008, para. A3.55):

- Expenditures on Research and Development (R\&D) are now capitalized as "intellectual property products" (SNA 2008, para. A3.46).

- Expenditures on military weapons systems (warships, submarines, military aircraft, tanks, etc.) are classified as "fixed assets" (SNA 2008, para. A3.55).

These changes in methodology have a large impact on the level of countries' GDP and statistics in terms of investment. The change from intermediate consumption to investment for R\&D increases value added* and consequently the GDP, while the change for military expenditures depends on the size of the countries' military (relatively small in OECD countries since it accounts for only $0.3 \%$ points on average).

By 2014, most OECD countries had implemented the new standards to their national accounts, while Turkey has planned to publish its results in 2015 according to the new SNA 08, and Chile and Japan in 2016.

* Value added is measured as the difference between output and intermediate consumption.

Source: "OECD Statistics brief - New standards for compiling national accounts" (February 2015 - No 20) http://www.oecd.org/std/na/new-standards-for-compiling-national-accounts-SNA2008-OECDSB20.pdf. 
Annex 3. Consolidation plans affecting public investment over 2011-2015

\begin{tabular}{|c|c|c|}
\hline Country & Measure & Amount and period \\
\hline Australia & $\begin{array}{l}20 \% \text { reduction in departmental capital budgets for relevant } \\
\text { government agencies and departments }\end{array}$ & AUS\$ 0.7 billion over $2012-2015$ \\
\hline Austria & Cuts in investment (especially federal railway infrastructure) & $€ 2$ billion over 2011-2016 \\
\hline Czech Republic & Reduce expenditure in infrastructure & CZK 3.1 billion in 2011 \\
\hline Estonia & Reduction in road maintenance and environmental investments & $€ 74.5$ million in 2009 \\
\hline Greece & Cut public investment budget & $€ 4$ billion over 2011-2015 \\
\hline Iceland & Cuts in maintenance and investments (mostly for road construction) & ISK196 billion over 2009-2015 \\
\hline Ireland & Cuts in capital spending & $€ 3$ billion over 2011-2014 \\
\hline Luxembourg & Cuts in investment expenditure & $€ 2.3$ billion over 2011-2015 \\
\hline Portugal & $\begin{array}{l}\text { Postponing high-speed rail links and commitments to no new road } \\
\text { infrastructure. } \\
\text { Reduction in capital expenditure }\end{array}$ & $2.3 \%$ of GDP over $2010-2013$ \\
\hline Slovak Republic & Decrease in investment expenditure & $€ 2.1$ billion over 2011-2015 \\
\hline Slovenia & Reduce investment expenditure & $€ 2$ billion over $2010-2013$ \\
\hline Spain & $\begin{array}{l}\text { Infrastructure cuts } \\
\text { Other central government investments reduced by } 25 \% \text { in } 2011-13\end{array}$ & $€ 33$ billion over 2011-2013 \\
\hline Sweden & $\begin{array}{l}\text { Roll-back of temporary infrastructure } \\
\text { programmes }\end{array}$ & SEK4.5 million over 2011-2015 \\
\hline Switzerland & $\begin{array}{l}\text { Cut in investment spending to reduce the fiscal stimulus measures of } \\
\qquad 2009\end{array}$ & CHF354 million over 2011-2012 \\
\hline
\end{tabular}

Source: OECD (2012), Restoring Public Finances, 2012 Update. 


\section{Annex 4. Methodology to elaborate governance indicators out of survey results}

The subnational governance indicators are based on detailed tables of answers to questions 5 and 6 of the survey, which include 20 different variables related to challenges perceived by respondents in the governance of infrastructure investment, from the design to the implementation and monitoring of infrastructure investment projects. The scale of responses from respondents varies on a 5-point scale to assess the degree of challenge linked to the statement.

The 20 variables are:

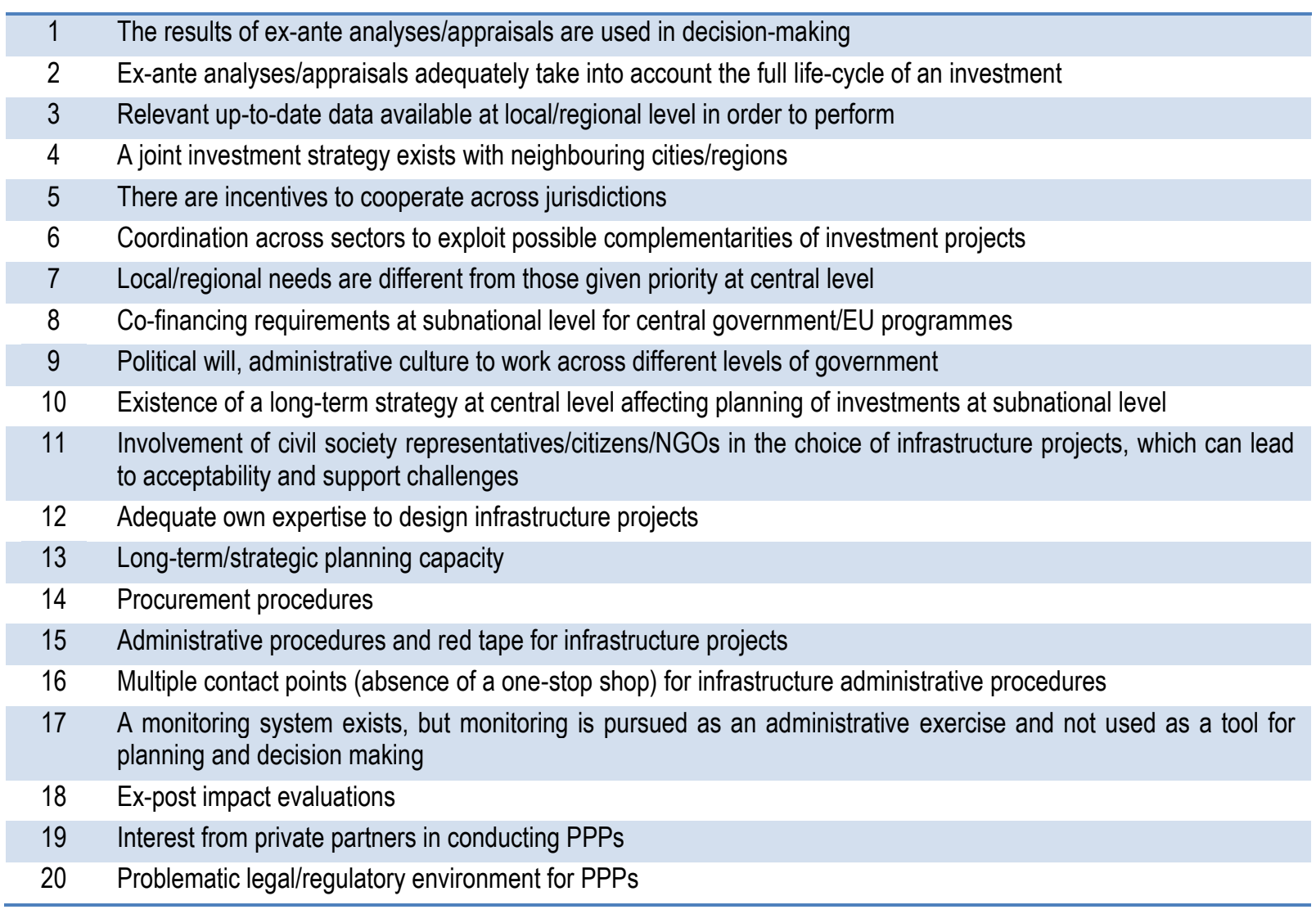

Each of these variables is weighted from 0 to 5 points according to the responses of the SNG: 0 point for the response "is a major challenge"; 2 points for "is somewhat of a challenge" 2.5 points for "no opinion", and 5 points for "is not a challenge". It was decided to amplify the scores of the two extremes ( 0 and 5) and to keep the category 'no opinion' as in most cases responding 'no opinion' is not a neutral response, as it reveals either lack of knowledge or lack of understanding of the challenge at stake. Since there are 20 variables, according to this ponderation, grades are ranged from 0 for the worst to 100 for the best ranking. The resulting score allows a classification of SNGs surveyed according to their perceived quality of governance of infrastructure investment at the local level.

This methodology was applied to the 255 respondents (SNGs) which have participated in the survey. Scores go from 6 to 86.5 out of 100. The average score is 39.7. Four groups have then been constituted:

- Score below 20: low quality of perceived subnational governance of investment

- Score between 20 and 40 (below average): medium quality of perceived subnational governance of investment

- Score between 40 and 60: high (above-average) quality of perceived subnational governance

- Score above 60: very high quality of perceived subnational governance of infrastructure investment 


\section{ENDNOTES}

${ }^{1}$ The baseline convergence model captures the long-term effect of human capital and physical investment on potential output for a panel of OECD countries and is augmented with public investment (Fournier, 2016).

${ }^{2}$ The definition of SNGs may differ throughout the chapter since the concept used by the System of National Accounts on which much of the quantitative data is based is slightly different from that used for the OECD-CoR survey. Furthermore, in countries where counties are not just an administrative entity but also have a political mandate, they are considered to be SNGs.

${ }^{3}$ Public-private partnerships, which account for less than $10 \%$ of public sector infrastructure investment in most OECD countries (Burger and Hawkesworth, 20), are also often not recorded in public investment.

${ }^{4}$ For instance, in Spain subnational investment of the Basque country still accounted for $63 \%$ of its 2008 level in 2016, while the fall of public investment has been much more pronounced in other autonomous communities.

5 This is largely explained by the budget consolidation measures, cutting the infrastructure budget by $30 \%$ between 2010 and 2011, to reduce budget deficit from $11.1 \%$ of GDP in 2010 to around 3\% by 2013.

${ }^{6}$ See http://www.oecd.org/effective-public-investment-toolkit/.

${ }^{7}$ Since 1971, the Austrian Conference on Spatial Planning (ÖROK) has served as a common platform for spatial planning coordination. It involves all federal ministries, the Länder, and the umbrella associations of municipalities and social partners and also manages EU Structural Funds programmes in Austria. Its executive body is chaired by the Federal Chancellor and includes all federal ministers and state governors, the presidents of the Austrian Union of Towns and the Austrian Union of Communities, and the presidents of the social and economic partners as advisors. Decisions are consensus-based. Thematic committees and working groups, formed by senior officials of the territorial authorities and social and economic partners, were set up at the administrative level to achieve ÖROK's tasks and projects.

${ }^{8}$ The Pearson correlation coefficient is $41.3 \%$; the correlation is statistically significant at the $95 \%$ confidence level. See European quality of governance index: https://nicholascharron.wordpress.com/european-quality-ofgovernment-index-eqi. 